\title{
Immunotherapy for Hepatocellular Carcinoma: A 2021 Update
}

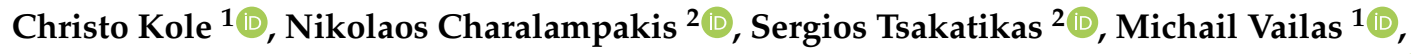 \\ Dimitrios Moris ${ }^{3}$, Efthymios Gkotsis ${ }^{1}$, Stylianos Kykalos ${ }^{4}$, Michalis V. Karamouzis ${ }^{5} *$ (D) and \\ Dimitrios Schizas ${ }^{1}$ (D)
}

1 First Department of Surgery, National and Kapodistrian University of Athens, Laikon General Hospital, 11527 Athens, Greece; christo.kole@gmail.com (C.K.); mike_vailas@yahoo.com (M.V.); thymiosgotsis@yahoo.gr (E.G.); schizasad@gmail.com (D.S.)

2 Department of Medical Oncology, Metaxa Cancer Hospital, 18537 Athens, Greece; nick301178@yahoo.com (N.C.); tsakatikas.s@gmail.com (S.T.)

3 Department of Surgery, Duke University School of Medicine, Durham, NC 27707, USA; dimitrios.moris@duke.edu

4 Second Propedeutic Department of Surgery, National and Kapodistrian University of Athens, Laikon General Hospital, 11527 Athens, Greece; kykalos@gmail.com

5 Molecular Oncology Unit, Department of Biological Chemistry, National and Kapodistrian University of Athens, 11527 Athens, Greece

* Correspondence: mkaramouz@med.uoa.gr; Tel.: +30-6944290909

Received: 14 August 2020; Accepted: 30 September 2020; Published: 4 October 2020

Simple Summary: Hepatocellular carcinoma (HCC) is the most common liver malignancy associated with poor prognosis. Treatment options are limited partially due to resistance to traditional chemotherapeutic agents. Immunotherapy has changed the treatment landscape in metastatic and recurrent solid tumors such as malignant melanoma and non-small-cell lung cancer. Application of immunotherapy regimens in patients with HCC has led to encouraging results in terms of both safety and efficacy. In this review, we summarize the key points of currently available clinical trials and immunotherapy perspectives for HCC. Moreover, we explore the role of tumor microenvironment as a predictive and prognostic marker to immunotherapy response and its clinical implications.

\begin{abstract}
Hepatocellular carcinoma (HCC) is one of one of the most frequent liver cancers and the fourth leading cause of cancer-related mortality worldwide. Current treatment options such as surgery, neoadjuvant chemoradiotherapy, liver transplantation, and radiofrequency ablation will benefit only a very small percentage of patients. Immunotherapy is a novel treatment approach representing an effective and promising option against several types of cancer. The aim of our study is to present the currently ongoing clinical trials and to evaluate the efficacy of immunotherapy in HCC. In this paper, we demonstrate that combination of different immunotherapies or immunotherapy with other modalities results in better overall survival (OS) and progression-free survival (PFS) compared to single immunotherapy agent. Another objective of this paper is to demonstrate and highlight the importance of tumor microenvironment as a predictive and prognostic marker and its clinical implications in immunotherapy response.
\end{abstract}

Keywords: hepatocellular carcinoma; immunotherapy; immune checkpoint inhibitors; cancer vaccines; adoptive cellular immunotherapy; oncolytic viruses; tumor microenvironment; microsatellite instability 


\section{Introduction}

Hepatocellular carcinoma (HCC) accounts for more than $80 \%$ of primary liver cancers [1]. HCC is one of the most frequent cancers and the fourth leading cause of cancer-related mortality worldwide [2] accounting for more than 800,000 deaths globally [3]. Moreover, in the next 10 years, more than one million patients are expected to die from liver cancer as estimated by the World Health Organization (WHO) [4]. The majority of HCC patients are males in a ratio of 2.4 to 1 compared to women [5]. Hepatitis $\mathrm{B}$ or $\mathrm{C}(\mathrm{HBV}$ or $\mathrm{HCV}$ ) is the most common risk factor, accounting for $80 \%$ of $\mathrm{HCC}$ cases globally [6]. Other factors that increase the risk of HCC are cirrhosis, alcohol abuse, environmental toxins, non-alcoholic fatty liver disease (NAFLD), metabolic diseases such as diabetes mellitus and obesity, smoking, and genetic and hereditary disorders $[7,8]$.

The liver is considered an immune tolerant tissue, a characteristic that can be attributed to the particularities of its physiological function. Liver sinusoidal endothelial cells are exposed to a significant amount of bacterial antigens from portal circulation. These cells act as antigen-presenting cells (APCs) and regulate immunogenicity of liver microenvironment. Their role in normal liver function is to prevent acute response to bacterial agents in order to avoid unnecessary tissue damage [9]. As a result, liver sinusoidal endothelial cells express immunosuppressive molecules, such as programmed cell death ligand-1 (PD-L1). Another important cell type, Kupffer cells, are specialized liver-located macrophages that remove bacteria and produce immunosuppressive cytokines, such as IL-10 and prostaglandins [10]. They can also activate forkhead box P3 (FoxP3) in CD4+ T-cells resulting in proliferation of CD4+ regulatory T cells (Tregs), which negatively regulate immune response [11,12]. HCCs originate predominantly from hepatocytes and non-cancerous lesions (regenerative nodules and adenomas) from hepatic progenitor cells [13]. Increased PD-1 and PD-L1 expression has been observed in HCC patients [14,15], with the expression of PD-L1 associated with tumor aggressiveness and poor prognosis [16,17]. Among the molecular signaling pathways implicated in the pathogenesis of HCC, the $\mathrm{Wnt} / \beta$-catenin signaling pathway is one of the most frequently activated [18]. Recent studies have shown that $\mathrm{WNT} / \beta$-catenin signaling correlates with immune escape involving defective recruitment of dendritic cells by reducing CCL5 production and consequently impaired T-cell activity [19]. In addition, $\beta$-catenin activation promotes immune escape due to resistance to anti-PD-1 therapy in HCC $[15,18,19]$. Furthermore, high levels of Tregs in the HCC microenvironment are associated with poor prognosis. Dendritic cells (DCs), another type of APCs, also favor immune tolerance through the same mechanism [20]. Myeloid-derived suppressor cells (MDSCs) play a pivotal role in the development of immune tolerance through the expression of various cytokines (Figure 1), and their increased concentration in HCC tissues is linked to poorer prognosis [21,22]. For example, MDSCs promote tumor angiogenesis through vascular endothelial growth factor (VEGF) production and exert their immunosuppressive function through the induction of the CD4(+)CD25(+)Foxp3(+) Tregs [23,24]. MDSCs suppress natural killer (NK) cells, which limits the release of IFN- $\gamma$ [25]. Moreover, immunosuppressive tumor-associated macrophages (TAMs) and tumor-associated neutrophils (TANs) impair CD8+ cytotoxic T lymphocytes (CTLs) [26,27], while promoting accumulation and activation of CD4+CD25+Tregs [28]. Additionally, these cells express galectin-9, a ligand to TIM-3, an immune checkpoint protein expressed on Th1 cells surface. TIM3/galectin-9 pairing has a variety of effects on T-cells function, most often leading to suppression of immune response (Figure 1) [29]. 
A

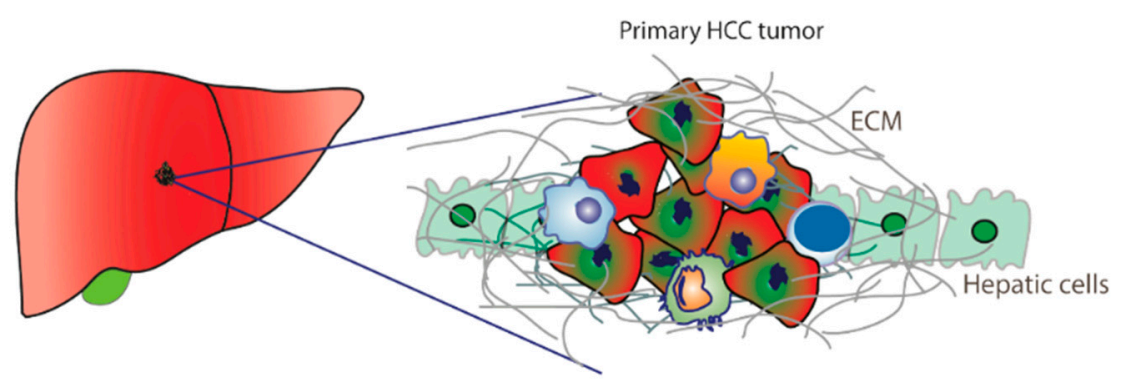

B

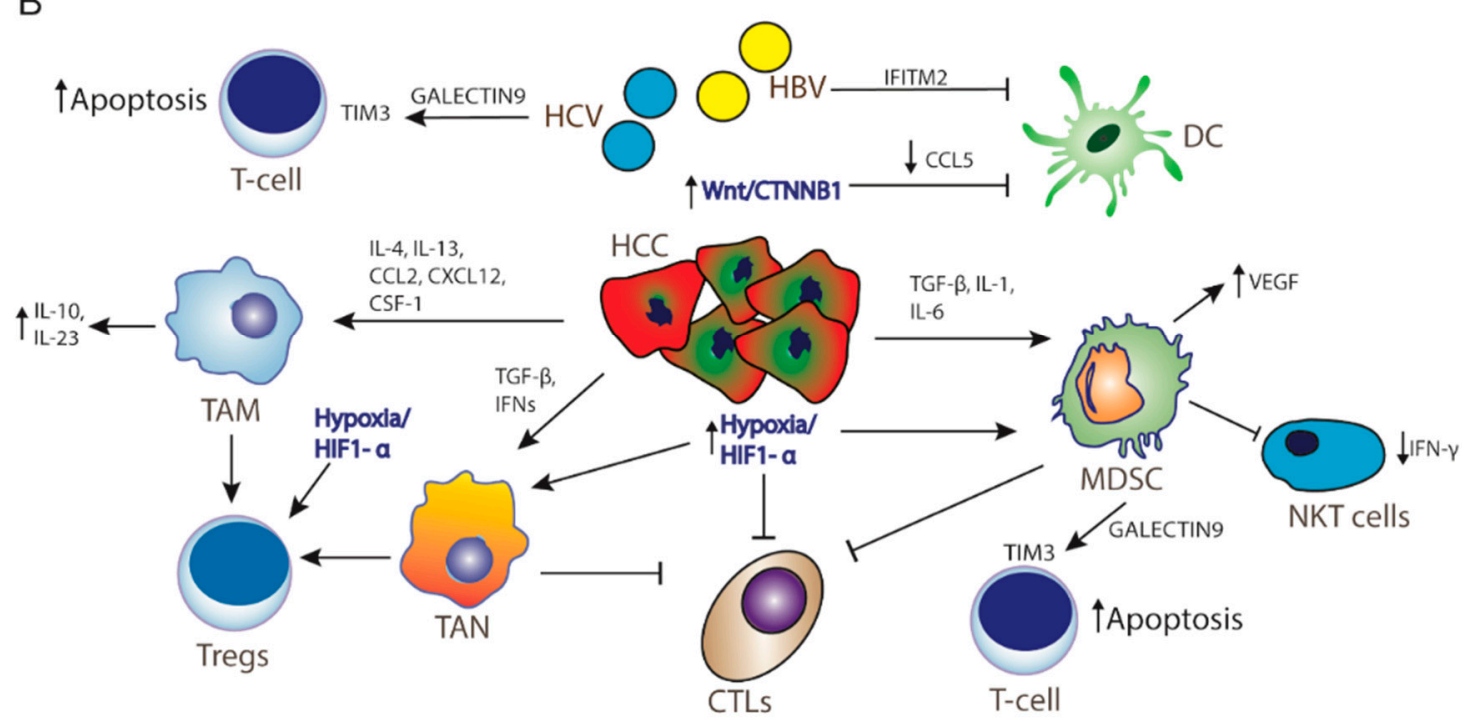

Figure 1. Hepatocellular carcinoma microenvironment. (A) Tumor microenvironment creates a barrier from extracellular matrix for immunotherapy as well as for cytotoxic drugs to act significantly in HCC. (B) Resistance mechanisms in HCC inducing tumor progression, immunosuppression, and cancer cell survival. Activation of Wnt/CTNNB1 signaling inhibits CCL5 production, thereby DC recruitment. Hypoxia and activation of HIF-1a promotes recruitment of MDSCs, Tregs, and TANs, whereas HCV infection and MDSCs promote T-cell apoptosis through activation of TIM3 receptor by Galectin-9 secretion by monocytes. HCC: hepatocellular carcinoma cells; ECM: extracellular matrix; TAM: tumor-associated macrophages; TAN: tumor-associated neutrophils; MDSCs: myeloid-derived suppressive cells; CTLs: cytotoxic T-lymphocytes; Tregs: CD4+ regulatory T cells; NKT cells: natural killer T cells; DC: dendritic cells IL: interleukin; TGF- $\beta$ : transforming growth factor beta; IFNs: interferons; HiF1-a: hypoxia-inducible factor-1 $\alpha$; VEGF: vascular endothelial growth factor; CCL2: C-C motif chemokine ligand 2; CCL5: CC-chemokine ligand 5; CXCL12: C-X-C motif chemokine 12; CSF-1: colony stimulating factor 1; IFITM2: interferon-induced transmembrane protein 2.

Diagnosis of HCC in the early-stage offers a wide array of treatment options that increase overall survival (OS) and improve quality of life. These patients can be treated with surgery [30], adjuvant or neoadjuvant chemoradiotherapy, liver transplantation, and radiofrequency ablation (RFA), albeit only one-third of patients are eligible for these approaches [31]. Unfortunately, due to late diagnosis, $70 \%$ to $80 \%$ of advanced HCC cases will not benefit from tumor resection [32]. As a result, prognosis is poor for most patients, with an average five-year survival rate of less than $15 \%$ and a median OS following diagnosis at 6 to 20 months $[5,33]$. Current treatment options for patients with unresectable HCC include transcatheter arterial chemoembolization (TACE) and the tyrosine kinase inhibitors sorafenib, regorafenib, and lenvatinib. These tyrosine kinase inhibitors are small molecules that inhibit multiple receptor tyrosine kinases implicated in tumor growth and angiogenesis, pathologic bone remodeling, drug resistance, and metastatic progression of cancer. HCC is a highly angiogenic tumor, 
thus inhibition of vascularization is a reasonable therapeutic strategy. Furthermore, inhibition of VEGF seems to enhance immunotherapy efficacy by exercising an immunomodulatory role in the tumor microenvironment. However, clinical benefit is still limited, and new therapeutic modalities are being explored [34-36].

Immunotherapy has proven to be effective and safe in treating a plethora of solid tumors, prolonging OS, and offering a tolerable toxicity profile [37-39]. Immunotherapy negates tumor-expressed extracellular ligands that suppress intrinsic immune response. Examples of such molecules are cytotoxic T-lymphocyte-associated antigen 4 (CTLA-4), programmed cell death protein-1 (PD-1), and its ligand, PD-L1. These proteins prevent T cells from recognizing and eliminating cancer cells [40]. This allows regular cells to avoid autoimmune destruction by downregulating T-cell activation [41]. CTLA-4 competitively inhibits binding of B7 ligands to the co-stimulatory receptor CD-28, while PD-1 binds to PD-L1 and PD-L2 ligands, preventing T-cell activity in peripheral tissues [41]. Overexpression of PD-L1 has been detected in the microenvironment of several solid tumors, such as esophageal, colon, pancreatic, gastric, lung, breast [42], and HCC [43]. Checkpoint inhibitors are antibodies that activate T-cell mediated antitumor responses by selectively blocking the checkpoint receptors PD-1, PD-L1, and CTLA-4 [44]. Targeting one or more of these receptors could mediate tumor regression in patients with melanoma, lung cancer, renal cell carcinoma, urothelial cancer, head and neck cancer, and other malignancies [45].

On the other hand, therapeutic cancer vaccines use a tumor-associated antigen (TAA) originating either from whole-cell tumor lysates and recombinant tumor peptides or full-length proteins or recombinant viruses encoding for TAAs. TAAs are transferred and presented by major histocompatibility complex (MHC) class I molecules in APCs to effectively induce activation of cytotoxic T-lymphocytes (CTLs) [46,47]. Another strategy in immune-regulated antitumor response is that of adoptive cell transfer (ACT). Immune cells are extracted from patients' peripheral blood and undergo genetic engineering to express chimeric antigen receptors (CARs). These cell membrane proteins bind to specific cancer antigens stimulating immune destruction of tumor cells [48].

\section{Immune Checkpoint Inhibitors in Hepatocellular Carcinoma}

Immune checkpoint inhibitors (ICIs) are monoclonal antibodies that block extracellular proteins that suppress antitumor immune response. Both tumor and immune system cells express these ligands. Although many molecules have been identified as mediating immune evasion by cancer cells, two categories have been thoroughly examined in clinical trials, PD-1 and CTLA-4 [49]. Currently, the US Food and Drug Administration (FDA) has approved checkpoint inhibitors for use in HCC (Table 1) [50], but many more promising markers are being investigated in animal models, and new agents are being tested in clinical trials. Lymphocyte activation gene 3 (LAG-3) is a membrane protein closely related to CD4. It is expressed by a variety of T cells, such as CD4, CD8, and Tregs, as well as by NK cells, DCs, and B cells. LAG-3 binds to MHC II of APCs and prevents recognition by T-cell receptors (TCRs), thus suppressing T-cell mediated immune response. LAG-3 expression is usually accompanied by increased PD-L1 levels in tumor tissue [51]. As a result, development of LAG-3 inhibitors and combination with existing anti-PD-1/PD-L1 molecules could have significant synergistic clinical benefit. However, no clinical trials are currently ongoing on HCC using these targets. 
Table 1. Immune checkpoint inhibitors—current clinical trials.

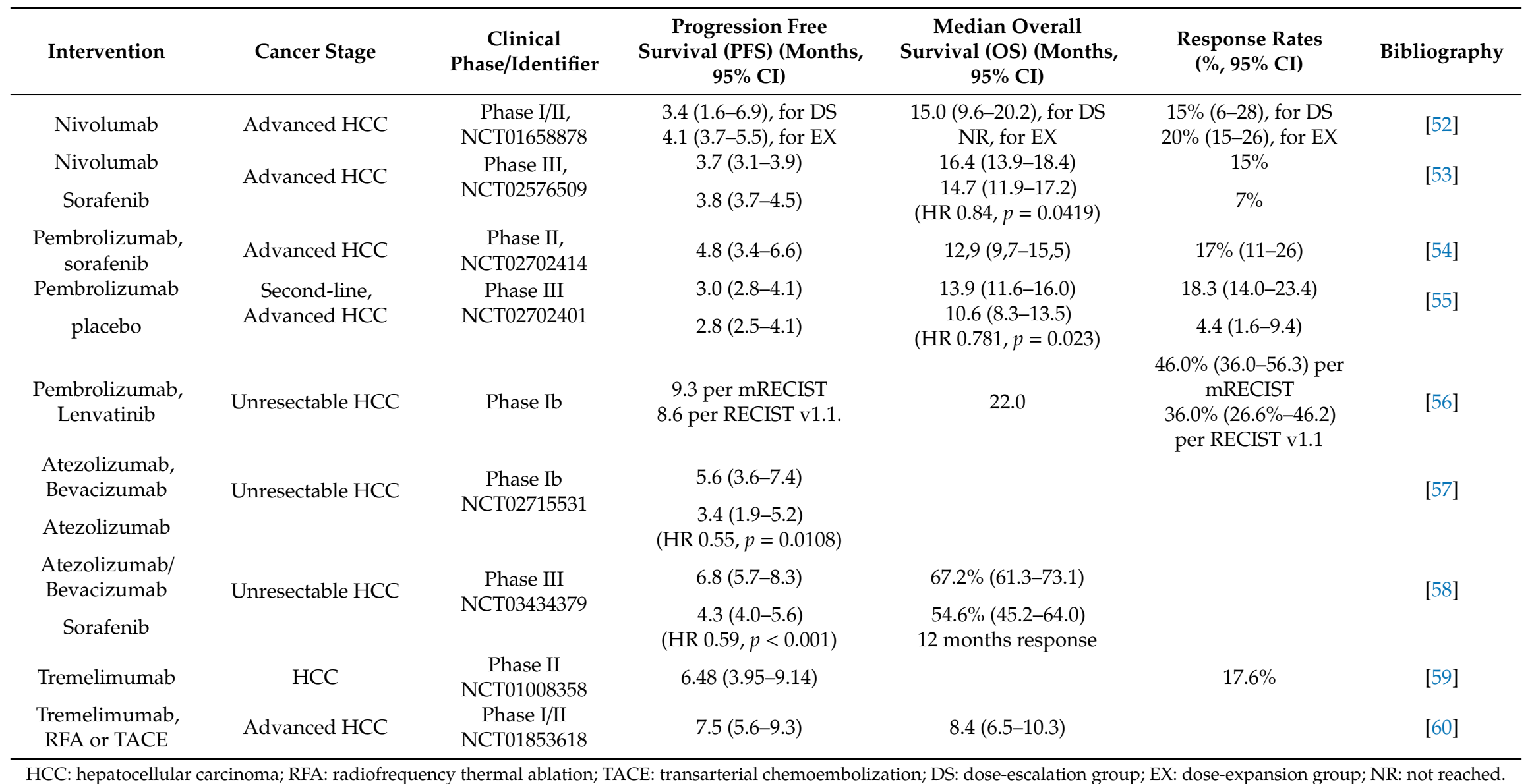




\subsection{Nivolumab}

Nivolumab is a human anti-PD-1 IgG4 monoclonal antibody that blocks PD-1 and was approved by the FDA in September 2017 as second-line treatment for HCC after progression of disease on first-line therapy with sorafenib. Several ongoing clinical trials are exploring the effectiveness and safety of nivolumab in patients with HCC [52]. In an open-label, non-comparative, phase I/II dose-escalation and expansion trial CheckMate 040 (NCT01658878), patients with a Child-Pugh score of 7 or less received $0.1 \mathrm{mg} / \mathrm{kg}$ to $10 \mathrm{mg} / \mathrm{kg}$ of nivolumab every 2 weeks (dose-escalation phase) and those with a Child-Pugh score of 6 or less, received $3 \mathrm{mg} / \mathrm{kg}$ every 2 weeks (dose-expansion phase). Child-Pugh is a score designed to assess the prognosis of chronic liver disease, primarily cirrhosis and to predict mortality, requirement of strength of treatment, and necessity of liver transplant [61]. Overall, this regimen resulted in substantial tumor reductions and had a manageable toxicity profile (Table 1). Patients in the dose-escalation phase achieved a median OS of 15 months (95\% CI: 9.6-20.2). Both groups performed similarly in terms of objective response rate (ORR). In the dose-escalation and dose-expansion group, ORR was $15 \%$ (95\% CI: 6-28) with a median duration of response at 17 months and $20 \%$ (95\% CI: 15-26) with median duration at 9.9 months, respectively [52]. The durable objective responses showed the potential of nivolumab for treatment of advanced HCC. Immunohistochemistry and RNA sequencing analysis revealed that PD-1- and PD-L1-positive patients were associated with improved survival and response. Patients with tumor PD-L1 $\geq 1 \%$ showed an increased median OS of 28.1 months (95\% CI 18.2-n.a.) compared to 16.6 months for those with tumor PD-L1 <1\% (95\% CI 14.2-20.2). Moreover, macrophage markers were not associated with OS, and increased CD3+ and CD8+ T-cells showed a non-significant trend towards improved OS, while patients with baseline AFP $<400 \mu \mathrm{g} / \mathrm{L}$ demonstrated numerically improved median OS of 16.8 months (95\% CI 13.3-20.2) compared with a median OS of 13.0 months (95\% CI 8.0-17.5) in patients with AFP $\geq 400 \mu \mathrm{g} / \mathrm{L}$ [62].

Another randomized phase III study, CheckMate 459 (NCT02576509), evaluated the efficacy of nivolumab vs. sorafenib, a tyrosine kinase inhibitor, as a first-line treatment [53]. OS in nivolumab-treated patients did not meet the predefined threshold of statistical significance (HR $0.84, p=0.0419)$. However, a clinically meaningful improvement in median OS of 16.4 months (95\% CI: 13.9-18.4) vs. 14.7 months (95\% CI: 11.9-17.2) for sorafenib-treated patients was demonstrated. ORRs in the nivolumab and sorafenib arms were $15 \%$ and $7 \%$, respectively. Interestingly, in the nivolumab arm, patients with PD-L1 $>1 \%$ benefited the most compared to those with PD-L1 $<1 \%$, ORR of $28.2 \%$ vs. $12.2 \%$, respectively. However, this did not translate to improved OS and progression-free survival (PFS). Nivolumab was, in general, more tolerable, with $22 \%$ of patients in the nivolumab arm manifesting grade $3 / 4$ treatment-related adverse events compared to $49 \%$ in the sorafenib arm, demonstrating a favorable safety profile consistent with previous reports [53]. The role of nivolumab in HCC treatment is currently being explored in clinical trials, either as monotherapy or in combination with other modalities. Notable examples are a phase II/III study (NCT04268888) in addition to TACE [63], phase I/II studies (NCT02423343, NCT03893695, NCT03059147) in addition to a novel transforming growth factor-beta (TGF- $\beta$ ) receptor I kinase inhibitors [64-66] and as adjuvant therapy (NCT03383458, NCT03572582) in patients at high risk of recurrence after resection or RFA compared to placebo $[67,68]$.

\subsection{Pembrolizumab}

Pembrolizumab is an anti-PD-1 IgG4 antibody that was granted accelerated approval by FDA in November 2018 as a second-line treatment after progression or high toxicity with previous sorafenib, after showing increased effectiveness and tolerability in the KEYNOTE-224 phase II study (NCT02702414) [54]. The ORR was 17\% (95\% CI: 11-26), with 1\% of patients showing complete and $16 \%$ partial response. Meanwhile, $44 \%$ of patients had stable disease, and $33 \%$ had progressive disease. Median OS reached 12.9 months (95\% CI: 9,7-15,5) and median PFS 4.9 months (95\% CI: 3,4-7,2). Disease control was reported in 64 of the 104 treated participants, $62 \%$ (95\% CI: 52-71), while grade $3 / 4$ treatment-related adverse events occurred at $25 \%$. One death associated with ulcerative 
esophagitis was attributed to treatment [54]. Further assessment is ongoing in the phase III studies KEYNOTE-240 [55] and KEYNOTE-394 [69]. In the KEYNOTE-240 study (NCT02702401), 413 patients were recruited (279 patients received pembrolizumab and 134 placebo). Even though the results of this study did not meet the prespecified cut-offs for statistical significance, patients treated with pembrolizumab demonstrated a better ORR, $18.3 \%$ (95\% CI: 14.0-23.4), compared to $4.4 \%$ (95\% CI: 1.6-9.4) in the placebo group, per response evaluation criteria in solid tumors version 1.1 (RECIST 1.1). OS was determined at 13.9 months (95\% CI: 11.6-16.0) and 10.6 months (95\% CI: 8.3-13.5) for pembrolizumab and placebo groups, respectively, with a hazard ratio (HR) estimated at 0.7 (95\% CI: $0.611-0.998, p=0.023$ ) (Table 1) [55]. Safety and efficacy of pembrolizumab in combination with sorafenib is being evaluated in a randomized phase I/II (NCT03211416) study [70], while KEYNOTE-394 (NCT03062358), a phase III study evaluating the effectiveness of pembrolizumab as second-line therapy after progression or intolerance to first-line sorafenib or oxaliplatin-based chemotherapy in Asian patients [69], are currently on recruitment phase and no results are published yet.

An open-label multicenter Phase $\mathrm{Ib}$ study reported that combination of pembrolizumab with lenvatinib (a multiple kinase inhibitor against VEGFR1, VEGFR2, and VEGFR3 kinases) had promising antitumor activity (Table 1) and manageable toxicities with grade $\geq 3$ treatment-related adverse events reported in $67 \%$ and grade 5 to $3 \%$ of patients [56]. Patients with unresectable HCC received lenvatinib (bodyweight $\geq 60 \mathrm{~kg}, 12 \mathrm{mg} ;<60 \mathrm{~kg}, 8 \mathrm{mg}$ ) orally daily and pembrolizumab $200 \mathrm{mg}$ intravenously on day 1 of a 21-day cycle. Authors reported a median OS at 22 months with a PFS at 9.3 months per modified RECIST (mRECIST) and 8.6 months per RECIST 1.1 [56]. Safety and efficacy of pembrolizumab in combination with lenvatinib is also evaluated in a randomized, double-blind, phase III (NCT03713593) study [71]. Moreover, pembrolizumab is also currently evaluated as adjuvant therapy after RFA or radiotherapy (NCT03753659, NCT03316872, NCT03099564, NCT03939975) [72-75].

\subsection{Atezolizumab}

Atezolizumab is an engineered IgG1 mAb targeting PD-L1. A randomized, phase Ib study (NCT02715531), in unresectable HCC patients, showed a manageable toxicity profile and a significantly better PFS in patients receiving atezolizumab plus bevacizumab compared to atezolizumab as monotherapy; 5.6 months (95\% CI: 3.6-7.4) vs. 3.4 months (95\% CI: 1.9-5.2), respectively [HR 0.55 (80\% CI: $0.40-0.74) ; p=0.0108$ ] (Table 1). Grade 3 or 4 adverse events occurred in $20 \%$ and $5 \%$ for atezolizumab/bevacizumab and atezolizumab as monotherapy, respectively [57]. The recent, open-label, phase III, IMbrave150 clinical trial (NCT03434379) further evaluated the effect of atezolizumab/bevacizumab in 336 patients compared to treatment with sorafenib in 165 patients [58]. This study presented a significantly lower HR for death in atezolizumab/bevacizumab treated patients compared to sorafenib [HR 0.58 (95\%CI: 0.42-0.79); $p<0.001$ ] (Table 1). Moreover, the combination of atezolizumab/bevacizumab significantly improved the 12-month OS rate to $67.2 \%$ (95\% CI: 61.3-73.1) compared to $54.6 \%$ (95\% CI: 45.2-64.0) in the sorafenib group. Median PFS was also significantly better; 6.8 months (95\% CI: 5.7-8.3) and 4.3 months (95\% CI: 4.0-5.6), respectively [HR 0.59 (95\% CI: $0.47-0.76) ; p<0.001]$. Moreover, Finn et al. reported an improvement in quality of life as expressed by median time to disease deterioration; 11.2 months (95\% CI: 6.0-NE) vs. 3.6 months (95\% CI: 3.0-7.0) [HR: 0.63 (95\% CI: 0.46-0.85)] and grade 3 or 4 adverse events occurring at $56.5 \%$ and $55.1 \%$ for atezolizumab/bevacizumab and sorafenib, respectively [58]. Following these encouraging results, the combination of atezolizumab/bevacizumab is a promising treatment option in previously untreated, unresectable HCC and gained FDA approval in the first line (National Comprehensive Cancer Network category 1 recommendation). Additionally, a COSMIC-312 Phase III study (NCT03755791) is designed to review the effect of atezolizumab plus cabozantinib (an oral tyrosine kinase inhibitor that targets VEGFR, MET, AXL, KIT, FLT-3, Tie-2, and RET) versus sorafenib in treatment-I advanced HCC; however, no results are yet available [76,77]. Previous analysis of cabozantinib improved the primary end point of OS relative to placebo, with a median of 10.2 versus 8.0 months (hazard ratio [HR] 0.76; 95\% CI $0.63-0.92 ; p=0.005$ ), and the secondary end point of PFS, with a median of 5.2 versus 1.9 months (HR: 
0.44; 95\% CI: $0.36-0.52 ; p<0.001$ ) [76]. Furthermore, two phase III clinical trials are currently recruiting patients using atezolizumab plus bevacizumab in combination with TACE or as adjuvant therapy to resection/RFA (NCT04102098, NCT04224636) [78,79].

Several ongoing studies are using anti-PD-1 antibodies, such as Tislelizumab (BGB-A317) compared to sorafenib (NCT03412773), SHR-1210 (NCT04297202, NCT02989922), and anti-PD-L1 durvalumab (NCT03847428, NCT03970616, NCT03778957, NCT04124991), avelumab (NCT03475953), currently being evaluated in a phase I/II or III clinical study either as first-line or second-line monotherapy [80-86] or in combination with other inhibitors as well as with locoregional treatment (NCT04310709, NCT03869034, NCT03794440, NCT03764293, NCT03755739, NCT03847428, NCT04273100, NCT03857815) [68,87-90]. However, none of these studies have posted any results yet.

\subsection{Tremelimumab}

Tremelimumab is a human IgG2 anti-CTLA-4 inhibitor [91]. A pilot study (NCT01008358) using tremelimumab studied the toxicity and tumor response in HCC patients. Most patients had advanced-stage disease with Child-Pugh score class B. A partial response rate at $17.6 \%$ and disease control rate at $76.4 \%$ was observed. Sangro et al. reported that the time to progression was 6.5 months (95\% CI: 3.95-9.14), with the treatment being, in general, well-tolerated [59]. In another study (NCT01853618), the safety and feasibility of tremelimumab combined with RFA or TACE were evaluated in patients with advanced HCC [60]. The primary results showed that $26.3 \%$ (95\% CI: 9.1-51.2\%) of patients achieved a confirmed partial response while the 6- and 12-month tumor PFS were reported at $57.1 \%$ and $33.1 \%$, respectively. Median time to tumor progression of 7.5 months (95\% CI: 5.6-9.3) and a median OS of 8.4 months (95\% CI: 6.5-10.3) were reported, concluding that the combination of tremelimumab and RFA or TACE may be a potential new treatment option for HCC patients [60].

The efficacy of immunotherapy can be improved through combinations with chemotherapy and local disease control interventions, such as TACE and RFA. Lysis of tumor and tumor-suppressive cells causes the release of TAAs into the tumor microenvironment (TME), thus inducing a Th1 immune response by sensitizing local CD8+ T-cells and DCs. This synergy, a.k.a. the abscopal effect, has been explored in clinical trials, showing improved clinical outcomes of immune-modulating agents, especially vaccines and CTLA-4 inhibitors, when combined with other treatment modalities [92].

\section{Vaccine Therapy in Hepatocellular Carcinoma}

Therapeutic vaccines include peptides, DCs, whole-cell vaccines, oncolytic viruses, and DNA agents to increase or achieve specific immune responses to tumor antigens [47]. Regarding this, several peptides, such as alpha-fetoprotein (AFP), multidrug resistance-associated protein 3 (MRP3), and glypican-3 (GPC3), have been examined to date (Table 2) and have proved to be well-tolerated and safe. 
Table 2. Vaccine therapy-current clinical trials.

\begin{tabular}{|c|c|c|c|c|c|c|}
\hline Intervention & Cancer Stage & $\begin{array}{c}\text { Clinical } \\
\text { Phase/Identifier }\end{array}$ & $\begin{array}{c}\text { Progression Free } \\
\text { Survival (PFS) } \\
\text { (Months, 95\% CI) }\end{array}$ & $\begin{array}{c}\text { Median Overall } \\
\text { Survival (OS) (Months, } \\
95 \% \mathrm{CI})\end{array}$ & $\begin{array}{c}\text { Response Rates } \\
(\%, 95 \% \mathrm{CI})\end{array}$ & Bibliography \\
\hline GPC3-vaccine & Advanced HCC & $\begin{array}{c}\text { Phase I, } \\
\text { UMIN000001395 }\end{array}$ & \multirow[t]{3}{*}{$3.4(2.1-4.6)$} & $9.0(8.0-10.0)$ & $91 \%$ & [93] \\
\hline $\begin{array}{c}\text { GPC3-vaccine, } \\
\text { Surgery and RFA }\end{array}$ & Adjuvant therapy & Phase II & & $20.1(14.7-25.5)$ & $\begin{array}{c}1 \text { year at } 24 \% \\
2 \text { years at } 52.4 \%\end{array}$ & [94] \\
\hline MRP3 & HLA-A24-positive & $\begin{array}{c}\text { Phase I } \\
\text { UMIN000005678 }\end{array}$ & & $14.0(9.6-18.5)$ & $72.7 \%$ & [95] \\
\hline DCs & HCC patients & Phase II & $\begin{array}{c}6 \text { months at } 33 \%, \\
1 \text { year at } 11 \%\end{array}$ & 5.5 & & [96] \\
\hline Ilixadencel & HCC patients & $\begin{array}{c}\text { Phase I } \\
\text { NCT01974661 }\end{array}$ & \multirow[t]{2}{*}{5.5} & $\begin{array}{l}7.4, \text { for } 10 \times 10^{6} \text { cells } \\
11.8, \text { for } 20 \times 10^{6} \text { cells }\end{array}$ & $73 \%$ & [97] \\
\hline JX-594 & $\begin{array}{l}\text { Advanced } \\
\text { HCC }\end{array}$ & $\begin{array}{c}\text { Phase II } \\
\text { NCT00554372 }\end{array}$ & & $\begin{array}{l}\text { 14.1, for high-dose } \\
6.7, \text { for low-dose }\end{array}$ & $\begin{array}{l}57 \% \text {, for high-dose } \\
67 \% \text {, for low-dose }\end{array}$ & [98] \\
\hline JX-594 & Advanced & Phase IIlb & $1.8(1.5-2.8)$ & 4.2 & & [99] \\
\hline BSC & $\begin{array}{l}\text { HCL, previously } \\
\text { treated with sorafenib }\end{array}$ & NCT01387555 & 2.8 (1.5-NA) & $4.4(\mathrm{HR}, 1.19, p=0.428)$ & & \\
\hline
\end{tabular}

HCC: hepatocellular carcinoma; GPC3: glypican-3; MRP3: multidrug resistance-associated protein 3; DC: dendritic cell; BSC, best supportive care. 


\subsection{Alpha-Fetoprotein (AFP) Peptide}

Alpha-fetoprotein (AFP) peptide is a $70 \mathrm{KDa}$ transporter, primarily expressed in the embryonic yolk sac of developing fetus and in the liver. Serum AFP levels become almost undetectable after birth; however, levels rise in HCC, and therefore, AFP is used as a biomarker [100]. Butterfield et al. used human AFP peptide epitopes previously identified [101] and created a human AFP-expressing replication-deficient adenovirus as a potential target for T-cell-based immunotherapy [102]. Therefore, these AFP constructs were tested as part of a phase I/II trial (NCT00093548) in two HCC patients who had an AFP-expressing tumor and previous treatment for HCC. This clinical trial showed that the vaccine was well-tolerated and safe, with no clinically significant adverse events. Moreover, both patients showed immunologic evidence of immunization with the AFP-specific CD8+ T cells appearing high. The first patient showed an AFP-specific T-cell response at 9 months while the second patient developed a strong AFP-specific $\mathrm{CD}^{+}$and $\mathrm{CD}^{+}$cellular response and an AFP-expressing replication-deficient adenovirus (AdV) neutralizing antibody response after 18 months [103].

\subsection{Glypican-3 (GPC3)}

Glypican-3 (GPC3) is a protein overexpressed in HCC tissues, but not in the healthy adult liver [104]. Various immunotherapies targeting glypican-3 have been developed so far (Table 2). In a phase I clinical study (UMIN000001395), GPC3-derived peptide vaccine was used in 33 patients with advanced HCC and reported that vaccination was well-tolerated, inducing a high rate of GPC3-specific CTL response [93]. One patient showed a partial response, and 19 patients showed stable disease 2 months after initiation of treatment. Furthermore, increased GPC3-specific CTLs, following vaccination correlated with significantly improved median OS of 9.0 months (95\% CI: 8.0-10.0) compared to patients who had low numbers of GPC3-specific CTLs [93]. Another phase II study showed that GPC3-positive patients treated with adjuvant vaccination had significantly lower recurrence rates than patients who received surgery only $(24 \%$ vs. $48 \%, p=0.047)$ at 1 year and $(52.4 \%$ vs. $61.9 \%, p=0.387)$ at 2 years [94].

\subsection{Multidrug Resistance-Associated Protein 3 (MRP3)}

Multidrug resistance-associated protein 3 (MRP3) is a carrier-type transport, member of ATP-binding cassette (ABC) transporters, and its high expression is related to various cancer cells [105]. Mizukoshi et al. reported an increase in MRP3 expression level in HCC tissue, significantly higher than in non-cancerous tissue $(p<0.05)$ [106]. MRP3-specific CTLs can be activated regardless of liver function, HCV infection status, AFP levels, and the stage of HCC. Moreover, Tomonari et al. demonstrated that MRP3 plays a vital role in resistance to sorafenib toxicity in HCC cells [107]. Thus, MRP3 consists a potential candidate for tumor antigen with strong immunogenicity in HCC immunotherapy. A phase I clinical trial (UMIN000005678) investigated the safety and immunogenicity of an MRP3-derived peptide (MRP3765) as a vaccine in 12 HLA-A24-positive HCC patients [95]. The vaccination was well-tolerated, inducing immunization in $72.7 \%$ of patients with the median OS being 14.0 months (95\% CI: 9.6-18.5). OS was longer compared with that in studies, including patients treated with hepatic arterial infusion chemotherapy without peptide vaccination, median OS 12.0 to 12.6 months $[95,108]$.

\subsection{NY-ESO-1 and MAGE-A}

NY-ESO-1 and MAGE-A: The New York esophageal squamous cell carcinoma-1 (NY-ESO-1) and the melanoma-antigen family A (MAGE-A) are two cancer-testis antigens that represent promising targets due to low expression in healthy tissue [109]. Flecken et al. reported specific CD8+ T-cell responses to NY-ESO-1b in 48\% of patients with NY-ESO-1 mRNA-positive HLA-A2-positive HCC. Moreover, the presence of these responses correlates with patient survival [110]. On the other hand, MAGE-A expression profile of HCC reports that $92.3 \%$ of the tumors expressed one MAGE-A gene [111], while another study reported that MAGE/tetramer+ CD8 cells of patients with HCC are 
able to recognize the MAGE-1 sequence 161-169 and the MAGE-3 sequence 271-279 [112]. These results lead to the conclusion that MAGE-A antigens may represent useful targets for tumor-specific immunotherapy in HCC patients, in addition to established treatment options. However, no studies have examined the clinical response using either NY-ESO-1 or MAGE-A vaccines in patients with HCC.

\subsection{Dendritic Cell Vaccine}

Dendritic cell vaccine: DCs are APCs, responsible for T-cell stimulation and antitumor immune response enhancement [113]. DCs are injected back into the patient after maturation and activation with a specific antigen in vitro. Studies using tumor cell lysate-loaded dendritic cell vaccine have shown antitumor effects in murine models [114]. At the same time, DC-derived exosomes form a new class of vaccines for cancer immunotherapy that can trigger potent antigen-specific antitumor immune responses and reshape the tumor microenvironment [115].

A phase I study of autologous dendritic cell-based immunotherapy was performed in unresectable primary HCC patients to evaluate the safety and feasibility of immunotherapy [116]. Eight out of ten patients included in this study had HCC, whereas the rest suffered from cholangiocarcinoma. The authors reported that immunization was well-tolerated in all patients, and no significant toxicity was detected. Moreover, one patient achieved tumor shrinkage and showed necrotic change on computed tomography, while in two other patients, serum levels of tumor markers decreased after vaccination. Another phase II clinical trial of 35 patients using DCs, pulsed ex vivo with a liver tumor cell line lysate (HepG2), resulted in generation of antigen-specific immune responses in some cases, while administration of these modified DCs was safe and well-tolerated with evidence of antitumor efficacy [96]. The median survival of the 35 treated patients was 5.5 months, while 6-month and 1-year survival rates were $33 \%$ and $11 \%$, respectively [96]. A phase I trial (NCT01974661) confirmed the safety of intra-tumoral injection of ilixadencel (pro-inflammatory allogeneic DCs stimulated by GM-CSF and IL-4), either as monotherapy or in combination with sorafenib, and was associated with increased tumor-specific $\mathrm{CD}^{+} \mathrm{T}$ cells. Rizell et al. reported that the median time to progression was 5.5 months, and OS ranged from 1.6 to 21.4 months (Table 2). The Kaplan-Meier median OS times were 7.5 months overall, 7.4 months for the dose of $10 \times 10^{6}$ viable cells, and 11.8 months for the dose of 20 $\times 10^{6}$ viable cells [97]. Moreover, in combination with TACE, DC infusion enhances the tumor-specific immune responses more effectively than TACE alone, although the effect is not sufficient to prevent HCC recurrence [117]. Further clinical trials are ongoing, NCT01821482, NCT02638857, NCT02882659, NCT03674073, NCT03203005 [118-121]; however, results have not been presented so far.

\subsection{Oncolytic Viruses}

Oncolytic viruses are viral particles engineered to cause direct lysis of tumor cells, resulting in the release of soluble cancer antigens, which induce antitumor neoantigen-specific CTL responses [122, 123]. A randomized phase II clinical trial (NCT00554372) studied the feasibility of two doses of JX-594 (Pexa-Vec), an oncolytic virus, in 30 HCC patients by infusing low- or high-dose JX-594 into tumors. Heo et al. reported significantly longer median OS in the high-dose arm compared to the low-dose arm, 14.1 months and 6.7 months, respectively (HR 0.39, $p=0.020$ ) (Table 2). The most common adverse reaction was flu-like syndrome with fever, rigor, and vomiting, which occurred in all patients within the first few days after treatment in a dose-dependent manner [98]. However, in patients who had been previously treated with sorafenib (NCT01387555), the median OS was not significantly different in patients treated with JX-594, 4.2 months, compared to best supportive care, 4.4 months, [HR 1.19 (95\% CI: 0.78-1.80); $p=0.428$ ) [99]. Currently, a phase III study (NCT02562755) is ongoing comparing JX-594, followed by sorafenib versus sorafenib alone [124].

\section{Adoptive Cell Transfer in Hepatocellular Carcinoma}

ACT, including NK cells, tumor-infiltrating lymphocytes (TILs), cytokine-induced killer cells (CIKs), and CAR T-cell therapy has shown considerable antitumor effects on HCC in several clinical trials 
(Table 3) [125-127]. Moreover, Zerbini et al. reported an increased NK-cell response in HCC patients after RFA [128]. Currently, only two phase II clinical trials evaluate safety and efficacy of autologous NK-cell reinfusion after curative liver resection (NCT01147380 [129] and NCT02008929 [130]).

\subsection{CIK Cells}

CIK cells: A phase I clinical study using autologous TILs following tumor resection in HCC patients reported no major adverse events after a median follow-up of 14 months. All patients remained alive, and $80 \%$ of them showed no evidence of disease [131]. The benefit of CIK cell treatment is supported by several other clinical studies [132-136], as well as a systematic review/meta-analysis including 13 phase II/III studies demonstrating significant superiority in prolonging the median OS, PFS, ORR, and disease control rate in HCC patients [137]. A phase III clinical study (NCT01749865) is completed; however, no results are yet available. Briefly, a phase II study (127 patients), a phase III study (200 patients), and a retrospective study (410 patients) reported similar results in patients who were treated with CIK cells as postoperative adjuvant therapy compared to no postoperative adjuvant therapy [132-134]. All studies reported significantly higher disease-free survival rates compared to control but no statistically significant difference in OS [132,133]. Pan et al. concluded that CIK-treated groups displayed significantly better OS compared to surgery alone in patients diagnosed with more than $5 \mathrm{~cm}$ tumors $(p=0.0002)$, while patients treated with more than eight cycles of cell transfusion showed significantly better OS than those treated with less than eight cycles $(p=0.0272)$. These results indicate that patients with large tumors might benefit more from CIK cell adjuvant treatment than patients with small tumors [133].

Combination of CIK immunotherapy with minimally invasive therapies for patients without previous surgery represents a potentially safe treatment modality for HCC [138-140]. Patients who had not previously received any surgery or chemoradiotherapy received CIK cells combination with TACE and RFA (CIK+TACE+RFA) (Table 3). No significant differences in disease control rates were reported between CIK cells' treatment combined with TACE and/or RFA or TACE and RFA alone. However, Kaplan-Meier analysis showed that patients in the CIK+TACE+RFA group compared to TACE+RFA alone had significantly longer OS; 56 months (95\% CI: 38.09-73.91) compared to 31 months (95\% CI: 24.53-37.47) and PFS at 17 months (95\% CI: 10.96-23.04) compared to 10 months (95\% CI: 8.57-11.44) [138].

\subsection{Chimeric Antigen Receptor T Cells (CAR-T)}

Chimeric antigen receptor T cells (CAR-T): Recent studies of HCC tumor xenografts in mice and in vitro demonstrated that engineered CAR-T cells expressing a GPC3 CAR could eliminate GPC3-positive HCC cells [141-144]. Therefore, phase I clinical studies designed to evaluate the safety and efficacy of CAR-GPC3 T-cell therapy alone (NCT03980288, NCT04121273, NCT03884751) or in combination with cyclophosphamide and fludarabine (NCT02905188) or other treatment options (NCT04093648, NCT03198546) are currently ongoing and in recruiting status [145-150]. The NCT02905188 and NCT03146234 studies (Table 3) reported that patients with advanced GPC3+ HCC (Child-Pugh A), receiving autologous CAR-GPC3 T-cell therapy following cyclophosphamide and fludarabine had a tolerable toxicity profile with no grade $3 / 4$ neurotoxicity. The OS rates at 6 months, 1 year, and 3 years were $50.3 \%, 42.0 \%$ and $10.5 \%$, respectively, with a median OS of 9.1 months (95\% CI: 1.5-20) [151]. The target lesions in two patients with partial response exhibited significant tumor shrinkage, while one patient with sustained stable disease was alive after 44.2 months [151]. Another phase I study (NCT02395250) [152] and a phase I/II study (NCT02723942) [153] have been completed; however, no results are yet posted. Moreover, clinical trials using CAR-T cells targeting other antigens are currently ongoing (NCT02587689, NCT03013712) [154,155]. 
Table 3. Adoptive cell transfer-current clinical trials.

\begin{tabular}{|c|c|c|c|c|c|c|}
\hline Intervention & Cancer Stage & $\begin{array}{c}\text { Clinical } \\
\text { Phase/Identifier }\end{array}$ & $\begin{array}{c}\text { Progression free } \\
\text { survival (PFS) } \\
\text { (Months, 95\% CI) }\end{array}$ & $\begin{array}{c}\text { Median Overall } \\
\text { Survival (OS) } \\
\text { (Months, 95\% CI) }\end{array}$ & $\begin{array}{c}\text { Response Rates } \\
(\%, 95 \% \mathrm{CI})\end{array}$ & Bibliography \\
\hline $\begin{array}{l}\text { CIK, TACE, and RFA } \\
\text { TACE, RFA }\end{array}$ & Advance HCC & & $\begin{array}{c}17(10.96-23.04) \\
10(8.57-11.44)\end{array}$ & $\begin{array}{l}56(38.09-73.91) \\
31(24.53-37.47)\end{array}$ & & [138] \\
\hline $\begin{array}{l}\text { CAR-T cells, } \\
\text { cyclophosphamide, } \\
\text { and fludarabine }\end{array}$ & $\begin{array}{c}\text { Advanced GPC3+ } \\
\text { HCC (Child-Pugh A) }\end{array}$ & $\begin{array}{c}\text { Phase I } \\
\text { NCT02905188 } \\
\text { NCT03146234 }\end{array}$ & $\begin{array}{l}3.2 \text { and } 3.6 \text { (for } \\
\text { two patients) }\end{array}$ & $9.1(1.5-20)$ & $\begin{array}{l}\text { Two partial } \\
\text { responses }\end{array}$ & [151] \\
\hline $\begin{array}{l}\text { Adjuvant-adoptive } \\
\text { immunotherapy } \\
\text { control }\end{array}$ & $\begin{array}{l}\text { Adjuvant treatment, } \\
\text { Resected HCC }\end{array}$ & & $\begin{array}{l}48 \%(37-59) \\
33 \%(22-43)\end{array}$ & & & [156] \\
\hline
\end{tabular}

HCC: hepatocellular carcinoma; RFA: radiofrequency thermal ablation; TACE: transarterial chemoembolization; CIK: cytokine induced killer cells; CAR-T: chimeric antigen receptor T cells. 
A study published in Lancet in 2000, which followed 150 patients for 4.4 years, assigned 76 patients for adoptive immunotherapy and 74 patients for no adjuvant treatment and concluded that adoptive immunotherapy is a safe and feasible treatment that can lower recurrence after surgery for HCC [156]. Takayama et al. showed that adoptive immunotherapy decreased recurrence frequency by $18 \%$ compared with controls (no adjuvant treatment) and reduced the risk of recurrence by $41 \%$ (95\% CI: $12-60, p=0.01)$. The immunotherapy group had a significantly longer recurrence-free survival $(p=$ $0.01)$ and disease-specific survival $(p=0.04)$ than the control group; however, no difference in median OS was identified between groups $(p=0.09)$ [156].

\section{Combinations Strategies of Immunotherapies}

Combination of nivolumab (NIVO) with ipilimumab (IPI) in sorafenib-treated patients has shown clinically significant responses and had an acceptable safety profile, with an ORR twice that of NIVO mono (31\% and $14 \%$, respectively) [157]. Patients were randomized to three groups (Table 4$)-(\mathrm{A})$ NIVO (1mg/kg) + IPI (3mg/kg) (four doses), (B) NIVO (3mg/kg) + IPI (1mg/kg) (four doses), or (C) NIVO $(3 \mathrm{mg} / \mathrm{kg})+$ IPI $(1 \mathrm{mg} / \mathrm{kg})$. Overall, ORR was $31 \%$ with a median $24-$ month OS rate at $40 \%$. Patients in arm A, B, and C had a median OS of 23 (95\% CI: 9-NA), 12 (95\% CI: 8-15) and 13 months (95\% CI: 7-33), respectively. Combination of NIVO + IPI was well-tolerated; $37 \%$ of patients had a grade 3-4 treatment-related adverse event while 5\% had grade 3-4 leading to discontinuation. Another study, reported combination therapy with nivolumab, ipilimumab, and cabozantinib (CABO) led to clinically meaningful responses (Table 4). Median PFS was 5.5 months for the patients receiving NIVO $(240 \mathrm{mg} /$ day $)+$ CABO $(40 \mathrm{mg} /$ day $)$ and 6.8 months for the NIVO $(3 \mathrm{mg} / \mathrm{kg})+$ IPI $(1 \mathrm{mg} / \mathrm{kg})+$ CABO (40mg/day), while median OS was not reached in either arm. Grade 3-4 treatment-related adverse events were reported in $15 \mathrm{pts}(42 \%)$ in the NIVO + CABO arm and $25 \mathrm{pts}(71 \%)$ in the NIVO + IPI + $\mathrm{CABO}$ arm and led to discontinuation in $1(3 \%)$ and $7(20 \%)$ patients, respectively [158]. Several other phase I/II clinical trials evaluating safety and efficacy of nivolumab in combination with ipilimumab are currently underway (NCT03682276, NCT04039607) [159-161], (NCT03510871, NCT03222076) [162,163]. Moreover, checkpoint inhibitors are further combined with oncolytic viruses in currently ongoing clinical trials (NCT03071094, NCT02432963, NCT04251117, NCT04248569) [164-167]; however, no results have been reported yet. Moreover, a multi-center, global, phase III study (NCT03298451) and another two, combining durvalumab/tremelimumab with TACE or RFA (NCT02821754, NCT03482102) are currently recruiting patients $[168,169]$.

Results have been reported so far from a phase I/II, open-label, randomized study (NCT02519348), concerning safety and efficacy of the recommended phase II doses of the durvalumab/tremelimumab combination for patients with HCC. In general, the treatment was well-tolerated, and no corticosteroids were required for severe immune-mediated adverse events, while enrollment to the phase II part of the study is ongoing [170]. Moreover, a multi-center, global, phase III study (NCT03298451) and another two combining durvalumab/tremelimumab with TACE or RFA (NCT02821754, NCT03482102) are currently recruiting patients $[168,169]$. Another study (UMIN000005820) reported that HCC patients treated with an autologous tumor lysate-pulsed DC vaccine combined with activated $\mathrm{T}$ cell transfer (ATVAC) resulted in improvement of median PFS and OS, 24.5 months (95\%CI: 7.8-41.2) and 97.7 months (95\% CI: 48.6-146.7), respectively, compared to 12.6 months (95\% CI: 6.9-18.3) and 41.0 months (95\% CI: 16.3-65.8) in the group receiving surgery alone (Table 4). In the treated group, patients with positive delayed-type hypersensitivity (DTH) had a better prognosis (PFS, $p=0.019$; OS, $p=0.025$ ). No adverse events of grade 3 or more were observed [171]. 
Table 4. Combination therapy—current clinical trials.

\begin{tabular}{|c|c|c|c|c|c|c|}
\hline Intervention & Cancer Stage & $\begin{array}{l}\text { Clinical Phase/ } \\
\text { Identifier }\end{array}$ & $\begin{array}{c}\text { Progression Free } \\
\text { Survival (PFS) } \\
\text { (Months, 95\% CI) }\end{array}$ & $\begin{array}{c}\text { Median Overall } \\
\text { Survival (OS) } \\
\text { (Months, 95\% CI) }\end{array}$ & $\begin{array}{c}\text { Response Rates } \\
\quad(\%, 95 \% \mathrm{CI})\end{array}$ & Bibliography \\
\hline $\begin{array}{l}\text { NIVO }(1 \mathrm{mg} / \mathrm{kg}) \\
\text { IPI }(3 \mathrm{mg} / \mathrm{kg})\end{array}$ & \multirow{3}{*}{$\begin{array}{c}\text { Sorafenib-treated } \\
\text { advanced hepatocellular } \\
\text { carcinoma patients }\end{array}$} & \multirow{3}{*}{ NCT01658878 } & $54.0(39.0-68.0)$ & $23.0(9.0-\mathrm{NA})$ & $32 \%$ & \multirow{3}{*}{ [157] } \\
\hline $\begin{array}{l}\text { NIVO (3mg/kg), } \\
\text { IPI (1mg/kg) }\end{array}$ & & & $43.0(29.0-58.0)$ & $12.0(8.0-15.0)$ & $31 \%$ & \\
\hline $\begin{array}{l}\text { NIVO }(3 \mathrm{mg} / \mathrm{kg}) \\
\text { IPI }(1 \mathrm{mg} / \mathrm{kg})\end{array}$ & & & $49.0(34.0-64.0)$ & $13.0(7.0-33.0)$ & $31 \%$ & \\
\hline NIVO, CABO & \multirow{2}{*}{$\begin{array}{l}\text { Sorafenib or experienced } \\
\text { advanced hepatocellular } \\
\text { carcinoma patients }\end{array}$} & \multirow{2}{*}{ NCT01658878 } & 5.5 & Not reached & $81 \%$ & \multirow{2}{*}{ [158] } \\
\hline NIVO, IPI, CABO & & & 6.8 & Not reached & $83 \%$ & \\
\hline $\begin{array}{c}\text { ATVAC } \\
\text { Surgery alone }\end{array}$ & Resected, invasive HCC & UMIN000005820 & $\begin{array}{l}24.5(7.8-41.2) \\
12.6(6.9-18.3)\end{array}$ & $\begin{array}{c}97.7(48.6-146.7) \\
41.0(16.3-65.8)\end{array}$ & & {$[171]$} \\
\hline
\end{tabular}

NIVO: nivolumab; IPI: ipilimumab; CABO: cabozantinib, HCC: hepatocellular carcinoma; ATVAC: autologous tumor lysate-pulsed dendritic cell vaccine plus ex vivo activated T cell transfer. 


\section{Hepatitis Infection and Immunotherapy}

As previously mentioned, most cases of HCC are associated with chronic hepatitis infection. Thus, TME in HCC usually presents elements of chronic inflammation. Liver tissue in patients with HCC has a high concentration of CD8+ CTLs [172]; however, they are suppressed and proliferate at a reduced rate. This T-Cell exhaustion is linked to overexpression of co-stimulatory molecules, such as B7-1 (CD80) and B7-2 on CD4+ T-cells and CD137 on CD8+ and NK cells. These molecules are vital points in the signaling of immune checkpoint pathways B7-CD28/CTLA-4 and PD-L1/PD-L2/PD-1 [173]. This immunosuppressive TME prevents tumor antigen detection by DCs via suppression of TAA and MHC molecules through the expression of inhibitory molecules (IL-10, TGF- $\beta$, VEGF) (Figure 1) [174]. Other important extracellular ligands that suppress antitumor immune response are TIM-3 and LAG-3 proteins and mutated MHC type I receptors [175]. The existence of a high amount of exhausted CD8+ T-cells that overexpress negative co-stimulatory molecules, such as PD-L1, represents a clue for the use of ICIs in HCC. A high level of PD-L1 is also an adverse prognostic factor, thus increasing the need for effective treatment in this group of patients [176]. Several clinical trials have evaluated the safety and efficacy of anti-PD-L1 in HCC patients with hepatitis, though no data have been powered for statistical comparison.

In the CheckMate 040 study, ORRs with nivolumab in patients infected with $\mathrm{HCV}, \mathrm{HBV}$, and those without viral hepatitis were $20 \%, 14 \%$, and $22 \%$, respectively. In the dose-expansion phase, 6 - and 9-month OS rates were $84 \%$ and $70 \%$ in HBV+ patients, $85 \%$ and $81 \%$ in $\mathrm{HCV}+$, while for the entire population of the study, $83 \%$ and $74 \%$, respectively [52]. In the CheckMate 459 study (nivolumab vs. sorafenib), a consistent effect on OS was also observed in advanced HCC with nivolumab, and benefit was noted for patients with HBV infection $[53,177]$.

Pembrolizumab, in the KEYNOTE-224 study, ORR was $13 \%$ in the subgroup of HBV+ or HCV+ and $20 \%$ in the uninfected subgroup; however, this difference was not statistically significant. Reduction from baseline in tumor target lesion size was $50 \%$ in the overall study population, $58 \%$ in uninfected patients, $57 \%$ in $\mathrm{HBV}+$, and $39 \%$ in $\mathrm{HCV}+$ patients [54]. In the phase 3 KEYNOTE-240 study, ORR in the whole population was $18 \%$ for pembrolizumab vs. $4 \%$ for placebo, while HBV+ patients achieved improved OS in comparison to placebo [HR 0.57 (CI: 0.35-0.94)], while no significant benefit appeared in $\mathrm{HCV}+$ patients [55]. In the phase III, IMbrave150 study, combination of atezolizumab and bevacizumab prolonged median PFS of HBV+ HCC compared to sorafenib, but this phenomenon did not appear in the population of HCC of non-viral etiology (median PFS, HBV+ HCC: 6.7 vs. 2.8 months; non-viral HCC: 7.1 vs. 5.6 months) [177].

A pooled analysis of previous studies by Li et al. assessed the efficacy of PD-1/PD-L1 blockade, either as monotherapy or in combination with other agents, in HCC patients according to their HBV status. No statistically significant difference was found between the two groups [odds ratio (OR) $0.68 ; 95 \%$ CI: $0.37-1.25]$, in terms of ORR, both in monotherapy and in combined therapy subgroups; however, HBV uninfected patients enjoyed statistically significant better disease control rates (DCRs) in comparison to those with HBV+ status (OR $0.49 ; 95 \%$ CI: $0.27-0.89$ in the monotherapy subgroup vs. OR 0.52 ; $95 \%$ CI: $0.27-0.99$ in the combination subgroup). HBV+ patients were also compared with $\mathrm{HCV}+$ in the same studies, and no significant difference was in ORRs and DCRs between those two subgroups. Interestingly, combinations of anti-PD-1/PD-L1 and anti-VEGF therapy showed similar ORRs and DCRs in all HCCs, regardless of HBV status [177].

\section{Predictive Biomarkers in HCC Immunotherapy}

Identification of patients' subgroups that would benefit from ICI remains a mainstay goal of cancer research and several biomarkers have been explored in solid tumors. Apart from PD-1/PD-L1 expression, another common predictor of tumor response is microsatellite instability (MSI). MSI refers to random mutations occurring in small repetitive elements due to a defective (mismatch repair) MMR system $[178,179]$. The accumulation of random mutations leads to increased neoantigen formation by the cells and target antigens for the immune system, promoting the expression of inflammatory 
cytokines and T-cell activation, thus rendering tumors susceptible to immunotherapy [180]. MSI high status (MSI-H) in HCC is rare, occurring in less than 3\% [181-185]. Interestingly, another analysis, which included 122 patients with HCC, revealed no tumors displaying a typical MSI-H phenotype defined by PCR-based MSI testing [185]. Despite its rarity, inflammation-mediated dysfunction of the MMR pathway can contribute to the accumulation of mutations during hepatitis-associated tumorigenesis. Moreover, tumor mutational burden (TMB) analysis is useful as an agnostic histologic indicator to identify patients who can benefit from ICIs, and the use of PD-1 inhibitors is recommended in this setting as second or later line treatment [181]. In a study by Ang, 755 specimens of HCC were analyzed for biomarkers affecting response to PD-1/PD-L1 inhibitors. Out of 542 cases assessed for MSI, one $(0.2 \%)$ was MSI-H and TMB high (TMB-H) [182]. Despite the low percentage of MSI-H, Kawaoka et al. reported encouraging results concerning response to immunotherapy. In their study, only two patients $(2.4 \%)$ were detected MSI-H with advanced HCC, one of which had a complete response to pembrolizumab [186].

On the other hand, genetic profiling of HCC using next-generation sequencing (NGS) has provided new opportunities to extensively analyze and identify those patients with HCC likely to benefit from targeted therapies [187]. High-resolution copy-number analysis and whole-exome sequencing has led to the identification of key genes, such as ARID1A, RPS6KA3, NFE2L2, and IRF2 and $\mathrm{Wnt} / \beta$-catenin signaling pathway involvement in HCC tumors by oxidative stress metabolism and Ras/mitogen-activated protein kinase (MAPK) pathways [188]. Functional analyses showed tumor suppressor properties for IRF2, whose inactivation, exclusively found in HBV-related tumors, led to impaired TP53 function [188]. $\beta$-catenin is shown to support HCC cell survival during the earlier stages of HCC by promoting EGFR signaling [189], while upregulation of LEF-1, a key transcription factor of $\beta$-catenin, is found also in hepatitis B surface antigen (HBsAg)-expressing HCC cell lines $[190,191]$. In addition, Wnt signaling supports more discrete functions, such as escaping immune surveillance. In the work of Harding et al., patients with advanced HCC were treated with anti-CTLA-4 monotherapy $[n=1]$, anti-PD-1/PD-L1 monotherapy [ $n=25]$, and anti PD-1/PD-L1 plus other agents, including anti-CTLA-4 [ $n=1]$, anti-LAG3 [ $n=2]$, and anti-KIR [ $n=2]$ ). NGS analysis disclosed 10 patients with WNT/ $\beta$-catenin mutations, none of whom had response to anti-PD-1 or anti-PD-L1 therapy at all, whereas $50 \%$ of $C T N N B 1$ WT patients had a response. WNT/ $\beta$-catenin signaling pathway were associated with lower DCRs and lower median PFS (2.0 vs. 7.4 months; HR, 9.2; 95\% CI, 2.9-28.8; $p<$ 0.0001 ) and OS (9.1 vs. 15.2 months; HR, 2.6; 95\% CI, 0.76-8.7; $p=0.11$ ) compared with those without such alterations [18].

\section{Conclusions}

Despite advances in cancer treatment and translational research, HCC is still associated with inferior outcomes and high mortality. However, many clinical trials seek to evaluate the efficacy of immunotherapy in HCC, including ICIs, cancer vaccines, ACT, and combinations with chemoradiotherapy or other molecularly targeted agents, yielding some encouraging results. So far, immunotherapeutic strategies have been proved safe; however, studies of single agent ICIs failed to show a survival benefit compared to combination therapies. Importantly, combinations of immunotherapy with other modalities have resulted in better OS and PFS. The optimization of the best strategy remains challenging, mainly because of the low TMB and immune-suppressive environment on which HCC arises. Despite the encouraging results of a few MSI-H tumor cases that responded to immunotherapy, MSI-H phenotype seems to be a rare phenomenon in HCC. On the other hand, genetic profiling of HCC using NGS and identification of patients with HCC likely to benefit from immunotherapies has shown promising results. Further analysis of NGS data will soon allow a better understanding of tumor heterogeneity and its potential role in treatment decision making by identifying HCC patients likely to benefit from immunotherapies. This is also supported by recent results in WNT/ $\beta$-catenin association with immune evasion and resistance to anti-PD-1 therapy. A low number of mutations hampers the production and release of neo-antigens and subsequently leads 
to low number of TILs. Additionally, HCC immunosuppressive TME creates a significant barrier to the efficacy of immunotherapy agents. Further research needs to focus on overcoming immunotherapy resistance by targeting multiple immune defects using combinatorial approaches of immunotherapy and cytotoxic agents in patients with HCC.

Funding: This research received no external funding.

Conflicts of Interest: The authors declare that they have no known competing financial interests or personal relationships that could have appeared to influence the work reported in this paper.

\section{References}

1. Yang, J.D.; Hainaut, P.; Gores, G.J;; Amadou, A.; Plymoth, A.; Roberts, L.R. A global view of hepatocellular carcinoma: Trends, risk, prevention and management. Nat. Rev. Gastroenterol. Hepatol. 2019, 16, 589-604. [CrossRef] [PubMed]

2. Global Burden of Disease Cancer Collaboration; Fitzmaurice, C.; Allen, C.; Barber, R.M.; Barregard, L.; Bhutta, Z.A.; Brenner, H.; Dicker, D.J.; Chimed-Orchir, O.; Dandona, R.; et al. Global, regional, and national cancer incidence, mortality, years of life lost, years lived with disability, and disability-adjusted life-years for 32 cancer groups, 1990 to 2015: A systematic analysis for the global burden of disease study. JAMA Oncol. 2017, 3, 524-548. [CrossRef] [PubMed]

3. Zhuo, Y.; Chen, Q.; Chhatwal, J.; Hoshida, Y. Changing epidemiology of hepatocellular carcinoma and role of surveillance. In Hepatocellular Carcinoma: Translational Precision Medicine Approaches; Hoshida, Y., Ed.; Humana Press Cham: Totowa, NJ, USA, 2019; pp. 53-67. [CrossRef]

4. World Health Organization. Projections of Mortality and Causes of Death, 2016 to 2060. Available online: http://www.who.int/healthinfo/global_burden_disease/projections/en/(accessed on 9 November 2018).

5. El-Serag, H.B. Hepatocellular carcinoma. N. Engl. J. Med. 2011, 365, 1118-1127. [CrossRef] [PubMed]

6. El-Serag, H.B. Epidemiology of viral hepatitis and hepatocellular carcinoma. Gastroenterology 2012, 142, 1264-1273.e1. [CrossRef]

7. Rawla, P.; Sunkara, T.; Muralidharan, P.; Raj, J.P. Update in global trends and aetiology of hepatocellular carcinoma. Wspótczesna Onkologia 2018, 22, 141-150. [CrossRef]

8. Villanueva, A. Hepatocellular carcinoma. N. Engl. J. Med. 2019, 380, 1450-1462. [CrossRef]

9. Jenne, C.N.; Kubes, P. Immune surveillance by the liver. Nat. Immunol. 2013, 14, 996-1006. [CrossRef]

10. Buonaguro, L.; Mauriello, A.; Cavalluzzo, B.; Petrizzo, A.; Tagliamonte, M. Immunotherapy in hepatocellular carcinoma. Ann. Hepatol. 2019, 18, 291-297. [CrossRef]

11. Schildberg, F.A.; Hegenbarth, S.I.; Schumak, B.; Scholz, K.; Limmer, A.; Knolle, P.A. Liver sinusoidal endothelial cells veto CD8 T cell activation by antigen-presenting dendritic cells. Eur. J. Immunol. 2008, 38, 957-967. [CrossRef]

12. Ormandy, L.A.; Hillemann, T.; Wedemeyer, H.; Manns, M.P.; Greten, T.F.; Korangy, F. Increased populations of regulatory $\mathrm{T}$ cells in peripheral blood of patients with hepatocellular carcinoma. Cancer Res. 2005, 65, 2457-2464. [CrossRef]

13. Tummala, K.S.; Brandt, M.; Teijeiro, A.; Graña, O.; Schwabe, R.F.; Perna, C.; Djouder, N. Hepatocellular carcinomas originate predominantly from hepatocytes and benign lesions from hepatic progenitor cells. Cell Rep. 2017, 19, 584-600. [CrossRef] [PubMed]

14. Kim, H.-D.; Song, G.-W.; Park, S.; Jung, M.K.; Kim, M.H.; Kang, H.J.; Yoo, C.; Yi, K.; Kim, K.H.; Eo, S.; et al. Association between expression level of PD1 by tumor-infiltrating CD8+ T cells and features of hepatocellular carcinoma. Gastroenterology 2018, 155, 1936-1950.e1917. [CrossRef] [PubMed]

15. Sia, D.; Jiao, Y.; Martinez-Quetglas, I.; Kuchuk, O.; Villacorta-Martin, C.; De Moura, M.C.; Putra, J.; Camprecios, G.; Bassaganyas, L.; Akers, N.K.; et al. Identification of an immune-specific class of hepatocellular carcinoma, based on molecular features. Gastroenterology 2017, 153, 812-826. [CrossRef] [PubMed]

16. Jung, H.I.; Jeong, D.; Ji, S.; Ahn, T.S.; Bae, S.H.; Chin, S.; Chung, J.C.; Kim, H.C.; Lee, M.S.; Baek, M.-J. Overexpression of PD-L1 and PD-L2 is associated with poor prognosis in patients with hepatocellular carcinoma. Cancer Res. Treat. 2017, 49, 246-254. [CrossRef] [PubMed] 
17. Calderaro, J.; Rousseau, B.; Amaddeo, G.; Mercey, M.; Charpy, C.; Costentin, C.; Luciani, A.; Zafrani, E.-S.; Laurent, A.; Azoulay, D.; et al. Programmed death ligand 1 expression in hepatocellular carcinoma: Relationship with clinical and pathological features. Hepatology 2016, 64, 2038-2046. [CrossRef]

18. Harding, J.J.; Nandakumar, S.; Armenia, J.; Khalil, D.N.; Albano, M.; Ly, M.; Shia, J.; Hechtman, J.F.; Kundra, R.; El Dika, I.; et al. Prospective genotyping of hepatocellular carcinoma: Clinical implications of next-generation sequencing for matching patients to targeted and immune therapies. Clin. Cancer Res. 2018, 25, 2116-2126. [CrossRef]

19. De Galarreta, M.R.; Bresnahan, E.; Molina-Sanchez, P.; Lindblad, K.E.; Maier, B.; Sia, D.; Puigvehí, M.; Miguela, V.; Casanova-Acebes, M.; Dhainaut, M.; et al. $\beta$-catenin activation promotes immune escape and resistance to anti-PD-1 therapy in hepatocellular carcinoma. Cancer Discov. 2019, 9, 1124-1141. [CrossRef]

20. Sachdeva, M.; Arora, S.K. Prognostic role of immune cells in hepatocellular carcinoma. EXCLI J. 2020, 19, 718-733. [CrossRef]

21. Kapanadze, T.; Gamrekelashvili, J.; Ma, C.; Chan, C.; Zhao, F.; Hewitt, S.; Zender, L.; Kapoor, V.; Felsher, D.W.; Manns, M.P.; et al. Regulation of accumulation and function of myeloid derived suppressor cells in different murine models of hepatocellular carcinoma. J. Hepatol. 2013, 59, 1007-1013. [CrossRef]

22. Zhou, J.; Liu, M.; Sun, H.; Feng, Y.; Xu, L.; Chan, A.W.H.; Tong, J.H.; Wong, J.; Chong, C.; Lai, P.B.S.; et al. Hepatoma-intrinsic CCRK inhibition diminishes myeloid-derived suppressor cell immunosuppression and enhances immune-checkpoint blockade efficacy. Gut 2017, 67, 931-944. [CrossRef]

23. Hoechst, B.; Ormandy, L.A.; Ballmaier, M.; Lehner, F.; Krüger, C.; Manns, M.P.; Greten, T.F.; Korangy, F. A new population of myeloid-derived suppressor cells in hepatocellular carcinoma patients induces CD4+CD25+Foxp3+ T Cells. Gastroenterology 2008, 135, 234-243. [CrossRef] [PubMed]

24. Schrader, J. The role of MDSCs in hepatocellular carcinoma-In vivo veritas? J. Hepatol. 2013, 59, 921-923. [CrossRef] [PubMed]

25. Zhang, H.; Li, Z.; Wang, L.; Tian, G.; Tian, J.; Yang, Z.; Cao, G.; Zhou, H.; Zhao, L.; Wu, Z.; et al. Critical role of myeloid-derived suppressor cells in tumor-induced liver immune suppression through inhibition of NKT cell function. Front. Immunol. 2017, 8, 129. [CrossRef] [PubMed]

26. Zhou, J.; Ding, T.; Pan, W.; Zhu, L.-Y.; Li, L.; Zheng, L. Increased intratumoral regulatory T cells are related to intratumoral macrophages and poor prognosis in hepatocellular carcinoma patients. Int. J. Cancer 2009, 125, 1640-1648. [CrossRef]

27. Michaeli, J.; Shaul, M.E.; Mishalian, I.; Hovav, A.-H.; Levy, L.; Zolotriov, L.; Granot, Z.; Fridlender, Z.G. Tumor-associated neutrophils induce apoptosis of non-activated CD8 T-cells in a TNF $\alpha$ and NO-dependent mechanism, promoting a tumor-supportive environment. Oncoimmunology 2017, 6, e1356965. [CrossRef]

28. Sharma, S.; Khosla, R.; David, P.; Rastogi, A.; Vyas, A.; Singh, D.; Bhardwaj, A.; Sahney, A.; Maiwall, R.; Sarin, S.K.; et al. CD4+CD25+CD127low regulatory T cells play predominant anti-tumor suppressive role in hepatitis B virus-associated hepatocellular carcinoma. Front. Immunol. 2015, 6. [CrossRef]

29. Li, H.; Wu, K.; Tao, K.; Chen, L.; Zheng, Q.; Lu, X.; Liu, J.; Shi, L.; Liu, C.; Wang, G.; et al. Tim-3/galectin-9 signaling pathway mediates T-cell dysfunction and predicts poor prognosis in patients with hepatitis B virus-associated hepatocellular carcinoma. Hepatology 2012, 56, 1342-1351. [CrossRef]

30. Arii, S.; Yamaoka, Y.; Futagawa, S.; Inoue, K.; Kobayashi, K.; Kojiro, M.; Makuuchi, M.; Nakamura, Y.; Okita, K.; Yamada, R. Results of surgical and nonsurgical treatment for small-sized hepatocellular carcinomas: A retrospective and nationwide survey in Japan. Hepatology 2000, 32, 1224-1229. [CrossRef]

31. Llovet, J.M.; Villanueva, A.; Lachenmayer, A.; Finn, R.S. Advances in targeted therapies for hepatocellular carcinoma in the genomic era. Nat. Rev. Clin. Oncol. 2015, 12, 408-424. [CrossRef]

32. El-Serag, H.B.; Rudolph, K.L. Hepatocellular Carcinoma: Epidemiology and Molecular Carcinogenesis. Gastroenterology 2007, 132, 2557-2576. [CrossRef]

33. Golabi, P.; Fazel, S.; Otgonsuren, M.; Sayiner, M.; Locklear, C.T.; Younossi, Z.M. Mortality assessment of patients with hepatocellular carcinoma according to underlying disease and treatment modalities. Medicine 2017, 96, e5904. [CrossRef] [PubMed]

34. Büttner, N.; Schmidt, N.; Thimme, R. Perspectives of immunotherapy in hepatocellular carcinoma (HCC). Zeitschrift für Gastroenterologie 2016, 54, 1334-1342. [CrossRef] [PubMed]

35. Llovet, J.M.; Ricci, S.; Mazzaferro, V.; Hilgard, P.; Gane, E.; Blanc, J.-F.; De Oliveira, A.C.; Santoro, A.; Raoul, J.-L.; Forner, A.; et al. Sorafenib in advanced hepatocellular carcinoma. N. Engl. J. Med. 2008, 359, 378-390. [CrossRef] [PubMed] 
36. Llovet, J.M.; Bruix, J. Systematic review of randomized trials for unresectable hepatocellular carcinoma: Chemoembolization improves survival. Hepatology 2003, 37, 429-442. [CrossRef]

37. Schizas, D.; Charalampakis, N.; Kole, C.; Mylonas, K.S.; Katsaros, I.; Zhao, M.; A Ajani, J.; Psyrri, A.; Karamouzis, M.V.; Liakakos, T. Immunotherapy for esophageal cancer: A 2019 update. Immunotherapy 2020, 12, 203-218. [CrossRef]

38. Schizas, D.; Charalampakis, N.; Kole, C.; Economopoulou, P.; Koustas, E.; Gkotsis, E.; Ziogas, D.; Psyrri, A.; Karamouzis, M.V. Immunotherapy for pancreatic cancer: A 2020 update. Cancer Treat. Rev. 2020, 86, 102016. [CrossRef]

39. Herzberg, B.; Campo, M.J.; Gainor, J. Immune checkpoint inhibitors in non-small cell lung cancer. Oncology 2017, 22, 81-88. [CrossRef]

40. Pardoll, D.M. The blockade of immune checkpoints in cancer immunotherapy. Nat. Rev. Cancer 2012, 12, 252-264. [CrossRef]

41. Disis, M.L. Mechanism of action of immunotherapy. Semin. Oncol. 2014, 41, S3-S13. [CrossRef]

42. Patel, S.P.; Kurzrock, R. PD-L1 Expression as a predictive biomarker in cancer immunotherapy. Mol. Cancer Ther. 2015, 14, 847-856. [CrossRef]

43. Wang, B.-J.; Bao, J.-J.; Wang, J.-Z.; Wang, Y.; Jiang, M.; Xing, M.-Y.; Zhang, W.-G.; Qi, J.-Y.; Roggendorf, M.; Lu, M.-J.; et al. Immunostaining of PD-1/PD-Ls in liver tissues of patients with hepatitis and hepatocellular carcinoma. World J. Gastroenterol. 2011, 17, 3322-3329. [CrossRef] [PubMed]

44. Rosenberg, S.A. Decade in review-cancer immunotherapy: Entering the mainstream of cancer treatment. Nat. Rev. Clin. Oncol. 2014, 11, 630-632. [CrossRef] [PubMed]

45. Brower, V. Checkpoint blockade immunotherapy for cancer comes of age. J. Natl. Cancer Inst. 2015, 107. [CrossRef] [PubMed]

46. Aranda, F.; Vacchelli, E.; Eggermont, A.; Galon, J.; Sautes-Fridman, C.; Tartour, E.; Zitvogel, L.; Kroemer, G.; Galluzzi, L. Trial watch: Peptide vaccines in cancer therapy. Oncoimmunology 2013, 2, e26621. [CrossRef]

47. Vacchelli, E.; Martins, I.; Eggermont, A.; Fridman, W.; Galon, J.; Sautès-Fridman, C.; Tartour, E.; Zitvogel, L.; Kroemer, G.; Galluzzi, L. Trial watch: Peptide vaccines in cancer therapy. Oncoimmunology 2012, 1, 1557-1576. [CrossRef]

48. Akce, M.; Zaidi, M.Y; Waller, E.K.; El-Rayes, B.F.; Lesinski, G.B. The potential of CAR T cell therapy in pancreatic cancer. Front. Immunol. 2018, 9, 2166. [CrossRef]

49. Webb, E.S.; Liu, P.; Baleeiro, R.; Lemoine, N.R.; Yuan, M.; Wang, Y.-H. Immune checkpoint inhibitors in cancer therapy. J. Biomed. Res. 2017, 32, 317-326. [CrossRef]

50. Greten, T.F.; Sangro, B. Targets for immunotherapy of liver cancer. J. Hepatol. 2017. [CrossRef]

51. Yarchoan, M.; Xing, N.; Luan, L.; Xu, H.; Sharma, R.; Popovic, A.; Pawlik, T.M.; Kim, A.K.; Zhu, Q.; Jaffee, E.M.; et al. Characterization of the immune microenvironment in hepatocellular carcinoma. Clin. Cancer Res. 2017, 23, 7333-7339. [CrossRef]

52. El-Khoueiry, A.B.; Sangro, B.; Yau, T.C.-C.; Crocenzi, T.S.; Kudo, M.; Hsu, C.; Kim, T.-Y.; Choo, S.-P.; Trojan, J.; Welling, T.H.; et al. Nivolumab in patients with advanced hepatocellular carcinoma (CheckMate 040): An open-label, non-comparative, phase 1/2 dose escalation and expansion trial. Lancet 2017, 389, 2492-2502. [CrossRef]

53. Yau, T.; Park, J.; Finn, R.; Cheng, A.-L.; Mathurin, P.; Edeline, J.; Kudo, M.; Han, K.-H.; Harding, J.; Merle, P.; et al. CheckMate 459: A randomized, multi-center phase III study of nivolumab (NIVO) vs. sorafenib (SOR) as first-line (1L) treatment in patients (pts) with advanced hepatocellular carcinoma (aHCC). Ann. Oncol. 2019, 30, v874-v875. [CrossRef]

54. Zhu, A.X.; Finn, R.S.; Edeline, J.; Cattan, S.; Ogasawara, S.; Palmer, D.; Verslype, C.; Zagonel, V.; Fartoux, L.; Vogel, A.; et al. Pembrolizumab in patients with advanced hepatocellular carcinoma previously treated with sorafenib (KEYNOTE-224): A non-randomised, open-label phase 2 trial. Lancet Oncol. 2018, 19, 940-952. [CrossRef]

55. Sharp, M.; Corp., D. Study of Pembrolizumab (MK-3475) vs. Best Supportive Care in Participants with Previously Systemically Treated Advanced Hepatocellular Carcinoma (MK-3475-240/KEYNOTE-240). 2016. Available online: https://clinicaltrials.gov/show/NCT02702401 (accessed on 11 June 2020).

56. Finn, R.S.; Ikeda, M.; Zhu, A.X.; Sung, M.W.; Baron, A.D.; Kudo, M.; Okusaka, T.; Kobayashi, M.; Kumada, H.; Kaneko, S.; et al. Phase Ib study of lenvatinib plus pembrolizumab in patients with unresectable hepatocellular carcinoma. J. Clin. Oncol. 2020, 38, 2960-2970. [CrossRef] [PubMed] 
57. Lee, M.; Ryoo, B.-Y.; Hsu, C.-H.; Numata, K.; Stein, S.; Verret, W.; Hack, S.; Spahn, J.; Liu, B.; Abdullah, H.; et al. Randomised efficacy and safety results for atezolizumab (Atezo) + bevacizumab (Bev) in patients (pts) with previously untreated, unresectable hepatocellular carcinoma (HCC). Ann. Oncol. 2019, 30 , v875. [CrossRef]

58. Finn, R.S.; Qin, S.; Ikeda, M.; Galle, P.R.; Ducreux, M.; Kim, T.-Y.; Kudo, M.; Breder, V.; Merle, P.; Kaseb, A.O.; et al. Atezolizumab plus bevacizumab in unresectable hepatocellular carcinoma. N. Engl. J. Med. 2020, 382, 1894-1905. [CrossRef]

59. Sangro, B.; Gomez-Martin, C.; De La Mata, M.; Iñarrairaegui, M.; Garralda, E.; Barrera, P.; Riezu-Boj, J.-I.; Larrea, E.; Alfaro, C.; Sarobe, P.; et al. A clinical trial of CTLA-4 blockade with tremelimumab in patients with hepatocellular carcinoma and chronic hepatitis C. J. Hepatol. 2013, 59, 81-88. [CrossRef]

60. Duffy, A.G.; Ulahannan, S.V.; Makorova-Rusher, O.; Rahma, O.; Wedemeyer, H.; Pratt, D.; Davis, J.L.; Hughes, M.S.; Heller, T.; Elgindi, M.; et al. Tremelimumab in combination with ablation in patients with advanced hepatocellular carcinoma. J. Hepatol. 2017, 66, 545-551. [CrossRef]

61. Tsoris, A.; Marlar, C.A. Use of the Child Pugh Score in Liver Disease; StatPearls: Treasure Island, FL, USA, 2020.

62. Sangro, B.; Melero, I.; Wadhawan, S.; Finn, R.S.; Abou-Alfa, G.K.; Cheng, A.-L.; Yau, T.; Furuse, J.; Park, J.-W.; Boyd, Z.; et al. Association of inflammatory biomarkers with clinical outcomes in nivolumab-treated patients with advanced hepatocellular carcinoma. J. Hepatol. 2020. [CrossRef]

63. The Clatterbridge Cancer Centre NHS Foundation Trust. Nivolumab in Combination with TACE/TAE for Patients with Intermediate Stage HCC. 2019. Available online: https://clinicaltrials.gov/show/NCT0426888 (accessed on 16 July 2020).

64. Eli Lilly and Company; Squibb, B.-M. A Study of Galunisertib (LY2157299) in Combination with Nivolumab in Advanced Refractory Solid Tumors and in Recurrent or Refractory NSCLC, or Hepatocellular Carcinoma. 2015. Available online: https://clinicaltrials.gov/show/NCT02423343 (accessed on 5 August 2020).

65. Suzhou Kintor Pharmaceutical Inc. Combination of GT90001 and Nivolumab in Patients with Metastatic Hepatocellular Carcinoma (HCC). 2019. Available online: https://clinicaltrials.gov/show/NCT03893695 (accessed on 14 September 2020).

66. SignalRX Pharmaceuticals, Inc.; University of California, San Diego. Phase 1 Study of SF1126 in Combination with Nivolumab in Patients with Advanced Hepatocellular Carcinoma. 2017. Available online: https: //clinicaltrials.gov/show/NCT03059147 (accessed on 14 August 2019).

67. Bristol-Myers Squibb; Ono Pharmaceutical Co. Ltd. A Study of Nivolumab in Participants with Hepatocellular Carcinoma Who Are at High Risk of Recurrence after Curative Hepatic Resection or Ablation. 2017. Available online: https://clinicaltrials.gov/show/NCT03383458 (accessed on 28 August 2020).

68. AIO-Studien-gGmbH; Bristol-Myers Squibb. Transarterial Chemoembolization in Combination with Nivolumab Performed for Intermediate Stage Hepatocellular Carcinoma. 2018. Available online: https: //clinicaltrials.gov/show/NCT03572582 (accessed on 14 July 2020).

69. Merck Sharp \& Dohme Corp. Study of Pembrolizumab (MK-3475) or Placebo Given With Best Supportive Care in Asian Participants with Previously Treated Advanced Hepatocellular Carcinoma (MK-3475-394/KEYNOTE-394). 2017. Available online: https://clinicaltrials.gov/show/NCT03062358 (accessed on 27 January 2020).

70. Roswell Park Cancer Institute; National Cancer Institute (NCI); Merck Sharp \& Dohme Corp. Sorafenib Tosylate and Pembrolizumab in Treating Patients with Advanced or Metastatic Liver Cancer. 2017. Available online: https://clinicaltrials.gov/show/NCT03211416 (accessed on 3 September 2020).

71. Merck Sharp \& Dohme Corp.; Eisai Inc. Safety and Efficacy of Lenvatinib (E7080/MK-7902) in Combination with Pembrolizumab (MK-3475) Versus Lenvatinib as First-Line Therapy in Participants with Advanced Hepatocellular Carcinoma (MK-7902-002/E7080-G000-311/LEAP-002). 2018. Available online: https:// clinicaltrials.gov/show/NCT03713593 (accessed on 10 April 2020).

72. Institut für Klinische Krebsforschung IKF GmbH at Krankenhaus Nordwest. IMMULAB-Immunotherapy with Pembrolizumab in Combination with Local Ablation in Hepatocellular Carcinoma (HCC). 2019. Available online: https:/clinicaltrials.gov/show/NCT03753659 (accessed on 28 May 2020).

73. University Health Network, Toronto. Study of Pembrolizumab and Radiotherapy in Liver Cancer. 2018. Available online: https://clinicaltrials.gov/show/NCT03316872 (accessed on 17 December 2019). 
74. Autumn McRee, M.D.; Merck Sharp \& Dohme Corp.; Hoosier Cancer Research Network. Pembrolizumab Plus Y90 Radioembolization in HCC Subjects. 2017. Available online: https://clinicaltrials.gov/show/NCT03099564 (accessed on 15 October 2019).

75. Sun Yat-sen University. Anti-PD-1therapy Combined with Thermal Ablation for Advanced HCC. 2019. Available online: https://clinicaltrials.gov/show/NCT03939975 (accessed on 19 August 2019).

76. Kelley, R.K.; Oliver, J.W.; Hazra, S.; Benzaghou, F.; Yau, T.; Cheng, A.-L.; Rimassa, L. Cabozantinib in combination with atezolizumab versus sorafenib in treatment-naive advanced hepatocellular carcinoma: COSMIC-312 Phase III study design. Future Oncol. 2020, 16, 1525-1536. [CrossRef]

77. Exelixis. Study of Cabozantinib in Combination with Atezolizumab versus Sorafenib in Subjects with Advanced HCC Who Have Not Received Previous Systemic Anticancer Therapy. 2018. Available online: https://clinicaltrials.gov/show/NCT03755791 (accessed on 25 September 2020).

78. Roche, H.-L. A Study of Atezolizumab Plus Bevacizumab Versus Active Surveillance as Adjuvant Therapy in Patients with Hepatocellular Carcinoma at High Risk of Recurrence After Surgical Resection or Ablation. 2019. Available online: https://clinicaltrials.gov/show/NCT04102098 (accessed on 29 September 2020).

79. Ludwig-Maximilians-University of Munich. Atezolizumab/Bevacizumab Followed by On-Demand TACE or Initial Synchronous Treatment with TACE and Atezolizumab/Bevacizumab. 2020. Available online: https://clinicaltrials.gov/show/NCT04224636 (accessed on 8 April 2020).

80. AVEO Pharmaceuticals, Inc.; AstraZeneca. A Study of Tivozanib in Combination with Durvalumab in Subjects with Untreated Advanced Hepatocellular Carcinoma. 2019. Available online: https://clinicaltrials. gov/show/NCT03970616 (accessed on 14 September 2020).

81. BeiGene. Phase 3 Study of Tislelizumab Versus Sorafenib in Participants With Unresectable HCC. 2017. Available online: https://clinicaltrials.gov/show/NCT03412773 (accessed on 29 June 2020).

82. Jiangsu HengRui Medicine Co., Ltd. A Study to Evaluate SHR-1210 in Subjects with Advanced HCC. 2016. Available online: https:/clinicaltrials.gov/show/NCT02989922 (accessed on 27 December 2017).

83. AstraZeneca. Assess Efficacy and Safety of Durvalumab Alone or Combined with Bevacizumab in High Risk of Recurrence HCC Patients after Curative Treatment. 2019. Available online: https://clinicaltrials.gov/ show/NCT03847428 (accessed on 25 September 2020).

84. Seoul National University Hospital. Safety and Efficacy Study of Radioembolization in Combination with Durvalumab in Locally Advanced and Unresectable HCC. 2019. Available online: https:/clinicaltrials.gov/ show/NCT04124991 (accessed on 18 October 2019).

85. The First Affiliated Hospital with Nanjing Medical University. SHR-1210 Combined with Apatinib Mesylate in the Perioperative Treatment of Hepatocellular Carcinoma. 2019. Available online: https:/clinicaltrials. gov/show/NCT04297202 (accessed on 27 August 2020).

86. Institut Bergonié; Bayer; Merck KGaA. A Phase I/II Study of Regorafenib Plus Avelumab in Solid Tumors. 2018. Available online: https://clinicaltrials.gov/show/NCT03475953 (accessed on 31 July 2020).

87. Sun Yat-sen University; Innovent Biologics, Inc. TAI Combined with PD-1 Inhibitor in Locally Advanced, Potentially Resectable HCC. 2019. Available online: https://clinicaltrials.gov/show/NCT03869034 (accessed on 27 August 2020).

88. Asan Medical Center; Samsung Medical Center; Bundang CHA Hospital. Combination of Regorafenib and Nivolumab in Unresectable Hepatocellular Carcinoma. 2020. Available online: https:/clinicaltrials.gov/ show/NCT04310709 (accessed on 18 June 2020).

89. Tianjin Medical University Cancer Institute and Hospital. PD-1 Monoclonal Antibody, Lenvatinib and TACE in the Treatment of HCC. 2019. Available online: https://clinicaltrials.gov/show/NCT04273100 (accessed on 17 February 2020).

90. Shanghai Zhongshan Hospital. Stereotactic Body Radiation Therapy Combined with Anti-PD-1 Antibody in Patients with Hepatocellular Carcinoma. 2019. Available online: https://clinicaltrials.gov/show/NCT03857815 (accessed on 19 March 2019).

91. Tremelimumab. Drugs R D 2010, 10, 123-132. [CrossRef]

92. Kumar, J.; Habib, N.A.; Huang, K.-W.; Podda, M.; Warwick, J.; Arasaradnam, R. Immunological basis of genesis of hepatocellular carcinoma: Unique challenges and potential opportunities through immunomodulation. Vaccines 2020, 8, 247. [CrossRef] 
93. Sawada, Y.; Yoshikawa, T.; Nobuoka, D.; Shirakawa, H.; Kuronuma, T.; Motomura, Y.; Mizuno, S.; Ishii, H.; Nakachi, K.; Konishi, M.; et al. Phase I trial of a glypican-3-derived peptide vaccine for advanced hepatocellular carcinoma: Immunologic evidence and potential for improving overall survival. Clin. Cancer Res. 2012, 18, 3686-3696. [CrossRef] [PubMed]

94. Sawada, Y.; Yoshikawa, T.; Ofuji, K.; Yoshimura, M.; Tsuchiya, N.; Takahashi, M.; Nobuoka, D.; Gotohda, N.; Takahashi, S.; Kato, Y.; et al. Phase II study of the GPC3-derived peptide vaccine as an adjuvant therapy for hepatocellular carcinoma patients. Oncoimmunology 2016, 5, e1129483. [CrossRef] [PubMed]

95. Mizukoshi, E.; Nakagawa, H.; Kitahara, M.; Yamashita, T.; Arai, K.; Sunagozaka, H.; Iida, N.; Fushimi, K.; Kaneko, S. Phase I trial of multidrug resistance-associated protein 3-derived peptide in patients with hepatocellular carcinoma. Cancer Lett. 2015, 369, 242-249. [CrossRef]

96. Palmer, D.H.; Midgley, R.S.; Mirza, N.; Torr, E.E.; Ahmed, F.; Steele, J.C.; Steven, N.M.; Kerr, D.J.; Young, L.S.; Adams, D.H. A phase II study of adoptive immunotherapy using dendritic cells pulsed with tumor lysate in patients with hepatocellular carcinoma. Hepatology 2009, 49, 124-132. [CrossRef]

97. Rizell, M.; Sternby Eilard, M.; Andersson, M.; Andersson, B.; Karlsson-Parra, A.; Suenaert, P. Phase 1 trial with the cell-based immune primer ilixadencel, alone, and combined with sorafenib, in advanced hepatocellular carcinoma. Front. Oncol. 2019, 9, 19. [CrossRef]

98. Heo, J.; Reid, T.; Ruo, L.; Breitbach, C.J.; Rose, S.; Bloomston, M.; Cho, M.; Lim, H.Y.; Chung, H.C.; Kim, C.W.; et al. Randomized dose-finding clinical trial of oncolytic immunotherapeutic vaccinia JX-594 in liver cancer. Nat. Med. 2013, 19, 329-336. [CrossRef]

99. Moehler, M.; Heo, J.; Lee, H.C.; Tak, W.Y.; Chao, Y.; Paik, S.W.; Yim, H.J.; Byun, K.S.; Baron, A.; Ungerechts, G.; et al. Vaccinia-based oncolytic immunotherapy pexastimogene devacirepvec in patients with advanced hepatocellular carcinoma after sorafenib failure: A randomized multicenter Phase IIb trial (TRAVERSE). Oncoimmunology 2019, 8, 1615817. [CrossRef]

100. Johnson, P.J. Role of alpha-fetoprotein in the diagnosis and management of hepatocellular carcinoma. J. Gastroenterol. Hepatol. 1999, 14, S32-S36. [CrossRef]

101. Butterfield, L.H.; Meng, W.S.; Koh, A.; Vollmer, C.M.; Ribas, A.; Dissette, V.B.; Faull, K.; Glaspy, J.A.; McBride, W.H.; Economou, J.S. T cell responses to HLA-A*0201-restricted peptides derived from human alpha fetoprotein. J. Immunol. 2001, 166, 5300-5308. [CrossRef]

102. Butterfield, L.H.; Koh, A.; Meng, W.; Vollmer, C.M.; Ribas, A.; Dissette, V.; Lee, E.; Glaspy, J.A.; McBride, W.H.; Economou, J.S. Generation of human T-cell responses to an HLA-A2.1-restricted peptide epitope derived from alpha-fetoprotein. Cancer Res. 1999, 59, 3134-3142. [PubMed]

103. Butterfield, L.H.; Economou, J.S.; Gamblin, T.C.; Geller, D.A. Alpha fetoprotein DNA prime and adenovirus boost immunization of two hepatocellular cancer patients. J. Transl. Med. 2014, 12, 86. [CrossRef] [PubMed]

104. Guo, M.; Zhang, H.; Zheng, J.; Liu, Y. Glypican-3: A new target for diagnosis and treatment of hepatocellular carcinoma. J. Cancer 2020, 11, 2008-2021. [CrossRef] [PubMed]

105. Kiuchi, Y.; Suzuki, H.; Hirohashi, T.; Tyson, C.A.; Sugiyama, Y. cDNA cloning and inducible expression of human multidrug resistance associated protein 3 (MRP3). FEBS Lett. 1998, 433, 149-152. [CrossRef]

106. Mizukoshi, E.; Honda, M.; Arai, K.; Yamashita, T.; Nakamoto, Y.; Kaneko, S. Expression of multidrug resistance-associated protein 3 and cytotoxic $\mathrm{T}$ cell responses in patients with hepatocellular carcinoma. $J$. Hepatol. 2008, 49, 946-954. [CrossRef] [PubMed]

107. Tomonari, T.; Takeishi, S.; Taniguchi, T.; Tanaka, T.; Tanaka, H.; Fujimoto, S.; Kimura, T.; Okamoto, K.; Miyamoto, H.; Muguruma, N.; et al. MRP3 as a novel resistance factor for sorafenib in hepatocellular carcinoma. Oncotarget 2016, 7, 7207-7215. [CrossRef]

108. Yamashita, T.; Arai, K.; Sunagozaka, H.; Ueda, T.; Terashima, T.; Yamashita, T.; Mizukoshi, E.; Sakai, A.; Nakamoto, Y.; Honda, M.; et al. Randomized, phase II study comparing interferon combined with hepatic arterial infusion of fluorouracil plus cisplatin and fluorouracil alone in patients with advanced hepatocellular carcinoma. Oncology 2011, 81, 281-290. [CrossRef]

109. Kerkar, S.P.; Wang, Z.F.; Lasota, J.; Park, T.; Patel, K.; Groh, E.; Rosenberg, S.A.; Miettinen, M.M. MAGE-A is more highly expressed than NY-ESO-1 in a systematic immunohistochemical analysis of 3668 cases. J. Immunother. 2016, 39, 181-187. [CrossRef]

110. Flecken, T.; Schmidt, N.; Hild, S.; Gostick, E.; Drognitz, O.; Zeiser, R.; Schemmer, P.; Bruns, H.; Eiermann, T.; Price, D.A.; et al. Immunodominance and functional alterations of tumor-associated antigen-specific CD8+ T-cell responses in hepatocellular carcinoma. Hepatology 2014, 59, 1415-1426. [CrossRef] 
111. Roch, N.; Kutup, A.; Vashist, Y.; Yekebas, E.; Kalinin, V.; Izbicki, J.R. Coexpression of MAGE-A peptides and HLA class I molecules in hepatocellular carcinoma. Anticancer Res. 2010, 30, 1617-1623.

112. Zerbini, A.; Pilli, M.; Soliani, P.; Ziegler, S.; Pelosi, G.; Orlandini, A.; Cavallo, C.; Uggeri, J.; Scandroglio, R.; Crafa, P.; et al. Ex vivo characterization of tumor-derived melanoma antigen encoding gene-specific CD8+cells in patients with hepatocellular carcinoma. J. Hepatol. 2004, 40, 102-109. [CrossRef]

113. Palucka, K.; Ueno, H.; Fay, J.; Banchereau, J. Dendritic cells and immunity against cancer. J. Intern. Med. 2011, 269, 64-73. [CrossRef] [PubMed]

114. Wang, Q.; Luan, W.; Warren, L.; Kadri, H.; Kim, K.W.; Goz, V.; Blank, S.; Isabel Fiel, M.; Hiotis, S.P. Autologous tumor cell lysate-loaded dendritic cell vaccine inhibited tumor progression in an orthotopic murine model for hepatocellular carcinoma. Ann. Surg. Oncol. 2016, 23, 574-582. [CrossRef] [PubMed]

115. Lu, Z.; Zuo, B.; Jing, R.; Gao, X.; Rao, Q.; Liu, Z.; Qi, H.; Guo, H.; Yin, H. Dendritic cell-derived exosomes elicit tumor regression in autochthonous hepatocellular carcinoma mouse models. J. Hepatol. 2017, 67, 739-748. [CrossRef]

116. Iwashita, Y.; Tahara, K.; Goto, S.; Sasaki, A.; Kai, S.; Seike, M.; Chen, C.L.; Kawano, K.; Kitano, S. A phase I study of autologous dendritic cell-based immunotherapy for patients with unresectable primary liver cancer. Cancer Immunol. Immunother. 2003, 52, 155-161. [CrossRef]

117. Mizukoshi, E.; Nakamoto, Y.; Arai, K.; Yamashita, T.; Mukaida, N.; Matsushima, K.; Matsui, O.; Kaneko, S. Enhancement of tumor-specific T-cell responses by transcatheter arterial embolization with dendritic cell infusion for hepatocellular carcinoma. Int. J. Cancer 2010, 126, 2164-2174. [CrossRef]

118. FullHope Biomedical Co., Ltd.; Taipei Veterans General Hospital, Taiwan. Dendritic Killer Cell-Based Immunotherapy for Solid Tumors. 2014. Available online: https://linicaltrials.gov/show/NCT02882659 (accessed on 30 August 2016).

119. Guangxi Medical University. A Study of DC-CIK to Treat Hepatocellular Carcinoma. 2013. Available online: https://clinicaltrials.gov/show/NCT01821482 (accessed on 12 April 2013).

120. Second Military Medical University. Immunotherapy Using Precision T Cells Specific to Multiple Common Tumor-Associated Antigen Combined with Transcatheter Arterial Chemoembolization for the Treatment of Advanced Hepatocellular Carcinoma. 2015. Available online: https://clinicaltrials.gov/show/NCT02638857 (accessed on 1 January 2016).

121. Chinese PLA General Hospital; Likang Life Sciences Holdings Limited. A Study Combining Personalized Neoantigen-Based Dendritic Cell Vaccine with Microwave Ablation for the Treatment of Hepatocellular Carcinoma. 2018. Available online: https://clinicaltrials.gov/show/NCT03674073 (accessed on 18 October 2018).

122. Kirn, D.; Martuza, R.L.; Zwiebel, J. Replication-selective virotherapy for cancer: Biological principles, risk management and future directions. Nat. Med. 2001, 7, 781-787. [CrossRef]

123. Liu, T.C.; Galanis, E.; Kirn, D. Clinical trial results with oncolytic virotherapy: A century of promise, a decade of progress. Nat. Clin. Pract. Oncol. 2007, 4, 101-117. [CrossRef]

124. SillaJen, Inc. Hepatocellular Carcinoma Study Comparing Vaccinia Virus Based Immunotherapy Plus Sorafenib vs. Sorafenib Alone. 2015. Available online: https://clinicaltrials.gov/show/NCT02562755 (accessed on 12 August 2019).

125. Li, S.; Yang, F.; Ren, X. Immunotherapy for hepatocellular carcinoma. Drug Discov. Ther. 2015, 9, 363-371. [CrossRef]

126. Jiang, J.; Wu, C.; Lu, B. Cytokine-induced killer cells promote antitumor immunity. J. Transl. Med. 2013, 11, 83. [CrossRef]

127. Jinushi, M.; Takehara, T.; Tatsumi, T.; Hiramatsu, N.; Sakamori, R.; Yamaguchi, S.; Hayashi, N. Impairment of natural killer cell and dendritic cell functions by the soluble form of MHC class I-related chain A in advanced human hepatocellular carcinomas. J. Hepatol. 2005, 43, 1013-1020. [CrossRef] [PubMed]

128. Zerbini, A.; Pilli, M.; Laccabue, D.; Pelosi, G.; Molinari, A.; Negri, E.; Cerioni, S.; Fagnoni, F.; Soliani, P.; Ferrari, C.; et al. Radiofrequency thermal ablation for hepatocellular carcinoma stimulates autologous NK-cell response. Gastroenterology 2010, 138, 1931-1942. [CrossRef] [PubMed]

129. Seigo Nishida; Florida Department of Health; Seigo Nishida, University of Miami. Safety Study of Liver Natural Killer Cell Therapy for Hepatoma Liver Transplantation. 2010. Available online: https: //clinicaltrials.gov/show/NCT01147380 (accessed on 10 March 2016). 
130. Samsung Medical Center. To Evaluate the Efficacy and Safety of MG4101 (Ex Vivo Expanded Allogeneic NK Cell). 2014. Available online: https://clinicaltrials.gov/show/NCT02008929 (accessed on 3 December 2015).

131. Jiang, S.S.; Tang, Y.; Zhang, Y.J.; Weng, D.S.; Zhou, Z.G.; Pan, K.; Pan, Q.Z.; Wang, Q.J.; Liu, Q.; He, J.; et al. A phase I clinical trial utilizing autologous tumor-infiltrating lymphocytes in patients with primary hepatocellular carcinoma. Oncotarget 2015, 6, 41339-41349. [CrossRef] [PubMed]

132. Hui, D.; Qiang, L.; Jian, W.; Ti, Z.; Da-Lu, K. A randomized, controlled trial of postoperative adjuvant cytokine-induced killer cells immunotherapy after radical resection of hepatocellular carcinoma. Dig. Liver Dis. 2009, 41, 36-41. [CrossRef]

133. Pan, K.; Li, Y.Q.; Wang, W.; Xu, L.; Zhang, Y.J.; Zheng, H.X.; Zhao, J.J.; Qiu, H.J.; Weng, D.S.; Li, J.J.; et al. The efficacy of cytokine-induced killer cell infusion as an adjuvant therapy for postoperative hepatocellular carcinoma patients. Ann. Surg. Oncol. 2013, 20, 4305-4311. [CrossRef]

134. Xu, L.; Wang, J.; Kim, Y.; Shuang, Z.Y.; Zhang, Y.J.; Lao, X.M.; Li, Y.Q.; Chen, M.S.; Pawlik, T.M.; Xia, J.C.; et al. A randomized controlled trial on patients with or without adjuvant autologous cytokine-induced killer cells after curative resection for hepatocellular carcinoma. Oncoimmunology 2016, 5, e1083671. [CrossRef]

135. Wang, F.S.; Liu, M.X.; Zhang, B.; Shi, M.; Lei, Z.Y.; Sun, W.B.; Du, Q.Y.; Chen, J.M. Antitumor activities of human autologous cytokine-induced killer (CIK) cells against hepatocellular carcinoma cells in vitro and in vivo. World J. Gastroenterol. 2002, 8, 464-468. [CrossRef]

136. Lee, J.H.; Lee, J.H.; Lim, Y.S.; Yeon, J.E.; Song, T.J.; Yu, S.J.; Gwak, G.Y.; Kim, K.M.; Kim, Y.J.; Lee, J.W.; et al. Adjuvant immunotherapy with autologous cytokine-induced killer cells for hepatocellular carcinoma. Gastroenterology 2015, 148, 1383-1391.e1386. [CrossRef]

137. Ma, Y.; Xu, Y.C.; Tang, L.; Zhang, Z.; Wang, J.; Wang, H.X. Cytokine-induced killer (CIK) cell therapy for patients with hepatocellular carcinoma: Efficacy and safety. Exp. Hematol. Oncol. 2012, 1, 11. [CrossRef]

138. Huang, Z.M.; Li, W.; Li, S.; Gao, F.; Zhou, Q.M.; Wu, F.M.; He, N.; Pan, C.C.; Xia, J.C.; Wu, P.H.; et al. Cytokine-induced killer cells in combination with transcatheter arterial chemoembolization and radiofrequency ablation for hepatocellular carcinoma patients. J. Immunother. 2013, 36, 287-293. [CrossRef]

139. Weng, D.S.; Zhou, J.; Zhou, Q.M.; Zhao, M.; Wang, Q.J.; Huang, L.X.; Li, Y.Q.; Chen, S.P.; Wu, P.H.; Xia, J.C. Minimally invasive treatment combined with cytokine-induced killer cells therapy lower the short-term recurrence rates of hepatocellular carcinomas. J. Immunother. 2008, 31, 63-71. [CrossRef] [PubMed]

140. Yoon, J.S.; Song, B.G.; Lee, J.-H.; Lee, H.Y.; Kim, S.W.; Chang, Y.; Lee, Y.B.; Cho, E.J.; Yu, S.J.; Sinn, D.H.; et al. Adjuvant cytokine-induced killer cell immunotherapy for hepatocellular carcinoma: A propensity score-matched analysis of real-world data. BMC Cancer 2019, 19, 523. [CrossRef] [PubMed]

141. Liu, X.; Wen, J.; Yi, H.; Hou, X.; Yin, Y.; Ye, G.; Wu, X.; Jiang, X. Split chimeric antigen receptor-modified T cells targeting glypican-3 suppress hepatocellular carcinoma growth with reduced cytokine release. Ther. Adv. Med. Oncol. 2020, 12. [CrossRef] [PubMed]

142. Wang, P.; Qin, W.; Liu, T.; Jiang, D.; Cui, L.; Liu, X.; Fang, Y.; Tang, X.; Jin, H.; Qian, Q. PiggyBac-engineered T cells expressing a glypican-3-specific chimeric antigen receptor show potent activities against hepatocellular carcinoma. Immunobiology 2020, 225. [CrossRef] [PubMed]

143. Batra, S.A.; Rathi, P.; Guo, L.; Courtney, A.N.; Fleurence, J.; Balzeau, J.; Shaik, R.S.; Nguyen, T.P.; Wu, M.F.; Bulsara, S.; et al. Glypican-3-Specific CAR T cells coexpressing IL15 and IL21 have superior expansion and antitumor activity against hepatocellular carcinoma. Cancer Immunol. Res. 2020, 8, 309-320. [CrossRef] [PubMed]

144. Wu, X.; Luo, H.; Shi, B.; Di, S.; Sun, R.; Su, J.; Liu, Y.; Li, H.; Jiang, H.; Li, Z. Combined antitumor effects of sorafenib and GPC3-CAR T cells in mouse models of hepatocellular carcinoma. Mol. Ther. 2019, 27, 1483-1494. [CrossRef]

145. Carsgen Therapeutics, Ltd.; NanJing PLA 81 Hospital; First Affiliated Hospital of Zhejiang University; RenJi Hospital. Chimeric Antigen Receptor T Cells Targeting Glypican-3. 2019. Available online: https: //clinicaltrials.gov/show/NCT03884751 (accessed on 15 October 2019).

146. Baylor College of Medicine; Center for Cell and Gene Therapy, Baylor College of Medicine; The Methodist Hospital System. Glypican 3-Specific Chimeric Antigen Receptor Expressing T Cells for Hepatocellular Carcinoma (GLYCAR). 2019. Available online: https://clinicaltrials.gov/show/NCT02905188 (accessed on 10 July 2020). 
147. The Affiliated Nanjing Drum Tower Hospital of Nanjing University Medical School. GPC3-targeted CAR-T Cell for Treating GPC3 Positive Advanced HCC. 2019. Available online: https://clinicaltrials.gov/show/ NCT04121273 (accessed on 11 October 2019).

148. Zhejiang University; Carsgen Therapeutics, Ltd. 4th Generation Chimeric Antigen Receptor T Cells Targeting Glypican-3. 2019. Available online: https://clinicaltrials.gov/show/NCT03980288 (accessed on 15 October 2019).

149. Second Affiliated Hospital of Guangzhou Medical University; Hunan Zhaotai Yongren Medical Innovation Co. Ltd.; Guangdong Zhaotai InVivo Biomedicine Co. Ltd.; First Affiliated Hospital, Sun Yat-Sen University. GPC3-T2-CAR-T Cells for Immunotherapy of Cancer With GPC3 Expression. 2017. Available online: https://clinicaltrials.gov/show/NCT03198546 (accessed on 26 November 2019).

150. Baylor College of Medicine; The Methodist Hospital System. T Cells Co-Expressing a Second Generation Glypican 3-Specific Chimeric Antigen Receptor with Cytokines Interleukin-21 and 15 as Immunotherapy for Patients with Liver Cancer (TEGAR). 2020. Available online: https://clinicaltrials.gov/show/NCT04093648 (accessed on 20 May 2020).

151. Shi, D.; Shi, Y.; Kaseb, A.O.; Qi, X.; Zhang, Y.; Chi, J.; Lu, Q.; Gao, H.; Jiang, H.; Wang, H.; et al. Chimeric antigen receptor-glypican-3 T-Cell therapy for advanced hepatocellular carcinoma: Results of phase 1 trials. Clin. Cancer Res. 2020. [CrossRef]

152. RenJi Hospital. Anti-GPC3 CAR T for Treating Patients with Advanced HCC. 2015. Available online: https://clinicaltrials.gov/show/NCT02395250 (accessed on 28 August 2019).

153. Fuda Cancer Hospital, Guangzhou. CAR-T Cell Immunotherapy for HCC Targeting GPC3. 2015. Available online: https://clinicaltrials.gov/show/NCT02723942 (accessed on 16 July 2020).

154. PersonGen BioTherapeutics (Suzhou) Co., Ltd.; The First People's Hospital of Hefei; Hefei Binhu Hospital. Phase I/II Study of Anti-Mucin1 (MUC1) CAR T Cells for Patients With MUC1+ Advanced Refractory Solid Tumor. 2015. Available online: https://clinicaltrials.gov/show/NCT02587689 (accessed on 5 December 2016).

155. First Affiliated Hospital of Chengdu Medical College. A Clinical Research of CAR T Cells Targeting EpCAM Positive Cancer. 2017. Available online: https://clinicaltrials.gov/show/NCT03013712 (accessed on 6 January 2017).

156. Takayama, T.; Sekine, T.; Makuuchi, M.; Yamasaki, S.; Kosuge, T.; Yamamoto, J.; Shimada, K.; Sakamoto, M.; Hirohashi, S.; Ohashi, Y.; et al. Adoptive immunotherapy to lower postsurgical recurrence rates of hepatocellular carcinoma: A randomised trial. Lancet 2000, 356, 802-807. [CrossRef]

157. Yau, T.; Kang, Y.-K.; Kim, T.-Y.; El-Khoueiry, A.B.; Santoro, A.; Sangro, B.; Melero, I.; Kudo, M.; Hou, M.-M.; Matilla, A.; et al. Nivolumab (NIVO) + ipilimumab (IPI) combination therapy in patients (pts) with advanced hepatocellular carcinoma (aHCC): Results from CheckMate 040. J. Clin. Oncol. 2019, 37, 4012. [CrossRef]

158. Yau, T.; Zagonel, V.; Santoro, A.; Acosta-Rivera, M.; Choo, S.P.; Matilla, A.; He, A.R.; Gracián, A.C.; El-Khoueiry, A.B.; Sangro, B.; et al. Nivolumab (NIVO) + ipilimumab (IPI) + cabozantinib (CABO) combination therapy in patients (pts) with advanced hepatocellular carcinoma (aHCC): Results from CheckMate 040. J. Clin. Oncol. 2020, 38, 478. [CrossRef]

159. Bristol-Myers Squibb; Ono Pharmaceutical Co. Ltd. An Immuno-Therapy Study to Evaluate the Effectiveness, Safety and Tolerability of Nivolumab or Nivolumab in Combination with Other Agents in Patients with Advanced Liver Cancer. 2012. Available online: https://clinicaltrials.gov/show/NCT01658878 (accessed on 30 June 2020).

160. Imperial College London; Bristol-Myers Squibb. Safety and Bioactivity of Ipilimumab and Nivolumab Combination Prior to Liver Resection in Hepatocellular Carcinoma. 2019. Available online: https:// clinicaltrials.gov/show/NCT03682276 (accessed on 11 June 2019).

161. Bristol-Myers Squibb. A Study of Nivolumab in Combination with Ipilimumab in Participants with Advanced Hepatocellular Carcinoma. 2019. Available online: https://clinicaltrials.gov/show/NCT04039607 (accessed on 23 September 2020).

162. National Health Research Institutes, Taiwan; National Taiwan University Hospital; Taipei Veterans General Hospital, Taiwan; National Cheng-Kung University Hospital; China Medical University Hospital; Chang Gung Memorial Hospital. Nivolumab Plus Ipilimumab as Neoadjuvant Therapy for Hepatocellular Carcinoma (HCC). 2018. Available online: https://clinicaltrials.gov/show/NCT03510871 (accessed on 27 April 2018). 
163. M.D. Anderson Cancer Center; National Cancer Institute (NCI). Nivolumab with or without Ipilimumab in Treating Patients with Resectable Liver Cancer. 2017. Available online: https://clinicaltrials.gov/show/ NCT03222076 (accessed on 19 August 2020).

164. Transgene. A Trial to Evaluate the Safety and Efficacy of the Combination of the Oncolytic Immunotherapy Pexa-Vec with the PD-1 Receptor Blocking Antibody Nivolumab in the First-Line Treatment of Advanced Hepatocellular Carcinoma (HCC). 2017. Available online: https://clinicaltrials.gov/show/NCT03071094 (accessed on 12 March 2020).

165. City of Hope Medical Center; National Cancer Institute (NCI). Vaccine Therapy and Pembrolizumab in Treating Patients with Solid Tumors That Have Failed Prior Therapy. 2015. Available online: https: //clinicaltrials.gov/show/NCT02432963 (accessed on 30 April 2019).

166. Geneos Therapeutics. GNOS-PV02 Personalized Neoantigen Vaccine, INO-9012 and Pembrolizumab in Subjects With Advanced HCC. 2020. Available online: https://clinicaltrials.gov/show/NCT04251117 (accessed on 19 May 2020).

167. Sidney Kimmel Comprehensive Cancer Center at Johns Hopkins; Bristol-Myers Squibb. DNAJB1-PRKACA Fusion Kinase Peptide Vaccine Combined with Nivolumab and Ipilimumab for Patients With Fibrolamellar Hepatocellular Carcinoma. 2020. Available online: https://clinicaltrials.gov/show/NCT04248569 (accessed on 13 April 2020).

168. AstraZeneca. Study of Durvalumab and Tremelimumab as First-Line Treatment in Patients with Advanced Hepatocellular Carcinoma. 2017. Available online: https://clinicaltrials.gov/show/NCT03298451 (accessed on 27 August 2020).

169. National Cancer Institute (NCI); National Institutes of Health Clinical Center (CC). A Pilot Study of Combined Immune Checkpoint Inhibition in Combination with Ablative Therapies in Subjects with Hepatocellular Carcinoma (HCC) or Biliary Tract Carcinomas (BTC). 2016. Available online: https://clinicaltrials.gov/show/ NCT02821754 (accessed on 13 May 2020).

170. Kelley, R.K.; Abou-Alfa, G.K.; Bendell, J.C.; Kim, T.-Y.; Borad, M.J.; Yong, W.-P.; Morse, M.; Kang, Y.-K.; Rebelatto, M.; Makowsky, M.; et al. Phase I/II study of durvalumab and tremelimumab in patients with unresectable hepatocellular carcinoma (HCC): Phase I safety and efficacy analyses. J. Clin. Oncol. 2017, 35, 4073. [CrossRef]

171. Shimizu, K.; Kotera, Y.; Aruga, A.; Takeshita, N.; Katagiri, S.; Ariizumi, S.; Takahashi, Y.; Yoshitoshi, K.; Takasaki, K.; Yamamoto, M. Postoperative dendritic cell vaccine plus activated T-cell transfer improves the survival of patients with invasive hepatocellular carcinoma. Hum. Vaccin. Immunother. 2014, 10, 970-976. [CrossRef] [PubMed]

172. An, J.L.; Ji, Q.H.; An, J.J.; Masuda, S.; Tsuneyama, K. Clinicopathological analysis of CD8-positive lymphocytes in the tumor parenchyma and stroma of hepatocellular carcinoma. Oncol. Lett. 2014, 8, 2284-2290. [CrossRef] [PubMed]

173. Chen, L.; Flies, D.B. Molecular mechanisms of T cell co-stimulation and co-inhibition. Nat. Rev. Immunol. 2013, 13, 227-242. [CrossRef] [PubMed]

174. Makarova-Rusher, O.V.; Medina-Echeverz, J.; Duffy, A.G.; Greten, T.F. The yin and yang of evasion and immune activation in HCC. J. Hepatol. 2015, 62, 1420-1429. [CrossRef] [PubMed]

175. Li, F.J.; Zhang, Y.; Jin, G.X.; Yao, L.; Wu, D.Q. Expression of LAG-3 is coincident with the impaired effector function of HBV-specific CD8(+) T cell in HCC patients. Immunol. Lett. 2013, 150, 116-122. [CrossRef]

176. Sun, D.W.; An, L.; Huang, H.Y.; Sun, X.D.; Lv, G.Y. Establishing peripheral PD-L1 as a prognostic marker in hepatocellular carcinoma patients: How long will it come true? Clin. Transl. Oncol. 2020. [CrossRef]

177. Li, B.; Yan, C.; Zhu, J.; Chen, X.; Fu, Q.; Zhang, H.; Tong, Z.; Liu, L.; Zheng, Y.; Zhao, P.; et al. Anti-PD-1/PD-L1 blockade immunotherapy employed in treating hepatitis B virus infection-related advanced hepatocellular carcinoma: A literature review. Front. Immunol. 2020, 11, 1037. [CrossRef]

178. Lower, S.S.; McGurk, M.P.; Clark, A.G.; Barbash, D.A. Satellite DNA evolution: Old ideas, new approaches. Curr. Opin. Genet. Dev. 2018, 49, 70-78. [CrossRef]

179. Veigl, M.L.; Kasturi, L.; Olechnowicz, J.; Ma, A.H.; Lutterbaugh, J.D.; Periyasamy, S.; Li, G.M.; Drummond, J.; Modrich, P.L.; Sedwick, W.D.; et al. Biallelic inactivation of hMLH1 by epigenetic gene silencing, a novel mechanism causing human MSI cancers. Proc. Natl. Acad. Sci. USA 1998, 95, 8698-8702. [CrossRef] 
180. Le, D.T.; Durham, J.N.; Smith, K.N.; Wang, H.; Bartlett, B.R.; Aulakh, L.K.; Lu, S.; Kemberling, H.; Wilt, C.; Luber, B.S.; et al. Mismatch repair deficiency predicts response of solid tumors to PD-1 blockade. Science 2017, 357, 409-413. [CrossRef] [PubMed]

181. Nakamura, Y.; Okamoto, W.; Shitara, K.; Kojima, T.; Morizane, C.; Naito, Y.; Yuki, S.; Kagawa, Y.; Narita, Y.; Nakashima, Y.; et al. Large-scale analyses of tumor mutation burdens (TMBs) across various advanced gastrointestinal (GI) malignancies in the nationwide cancer genome screening project, SCRUM-Japan GI-SCREEN. J. Clin. Oncol. 2018, 36, 12094. [CrossRef]

182. Ang, C.; Klempner, S.J.; Ali, S.M.; Madison, R.; Ross, J.S.; Severson, E.A.; Fabrizio, D.; Goodman, A.; Kurzrock, R.; Suh, J.; et al. Prevalence of established and emerging biomarkers of immune checkpoint inhibitor response in advanced hepatocellular carcinoma. Oncotarget 2019, 10, 4018-4025. [CrossRef] [PubMed]

183. Kazachkov, Y.; Yoffe, B.; Khaoustov, V.I.; Solomon, H.; Klintmalm, G.B.; Tabor, E. Microsatellite instability in human hepatocellular carcinoma: Relationship to p53 abnormalities. Liver 1998, 18, 156-161. [CrossRef] [PubMed]

184. Togni, R.; Bagla, N.; Muiesan, P.; Miquel, R.; O'Grady, J.; Heaton, N.; Knisely, A.S.; Portmann, B.; Quaglia, A. Microsatellite instability in hepatocellular carcinoma in non-cirrhotic liver in patients older than 60 years. Hepatol. Res. 2009, 39, 266-273. [CrossRef] [PubMed]

185. Goumard, C.; Desbois-Mouthon, C.; Wendum, D.; Calmel, C.; Merabtene, F.; Scatton, O.; Praz, F. Low levels of microsatellite instability at simple repeated sequences commonly occur in human hepatocellular carcinoma. Cancer Genomics Proteomics 2017, 14, 329-339. [CrossRef]

186. Kawaoka, T.; Ando, Y.; Yamauchi, M.; Suehiro, Y.; Yamaoka, K.; Kosaka, Y.; Fuji, Y.; Uchikawa, S.; Morio, K.; Fujino, H.; et al. Incidence of microsatellite instability-high hepatocellular carcinoma among Japanese patients and response to pembrolizumab. Hepatol. Res. 2020. [CrossRef]

187. Dominguez, D.A.; Wang, X.W. Impact of next-generation sequencing on outcomes in hepatocellular carcinoma: How precise are we really? J. Hepatocell Carcinoma 2020, 7, 33-37. [CrossRef]

188. Guichard, C.; Amaddeo, G.; Imbeaud, S.; Ladeiro, Y.; Pelletier, L.; Maad, I.B.; Calderaro, J.; Bioulac-Sage, P.; Letexier, M.; Degos, F.; et al. Integrated analysis of somatic mutations and focal copy-number changes identifies key genes and pathways in hepatocellular carcinoma. Nat. Genet. 2012, 44, 694-698. [CrossRef]

189. Kim, E.; Lisby, A.; Ma, C.; Lo, N.; Ehmer, U.; Hayer, K.E.; Furth, E.E.; Viatour, P. Promotion of growth factor signaling as a critical function of beta-catenin during HCC progression. Nat. Commun. 2019, 10, 1909. [CrossRef]

190. Tian, X.; Zhao, C.; Ren, J.; Ma, Z.M.; Xie, Y.H.; Wen, Y.M. Gene-expression profiles of a hepatitis B small surface antigen-secreting cell line reveal upregulation of lymphoid enhancer-binding factor 1. J. Gen. Virol. 2007, 88, 2966-2976. [CrossRef] [PubMed]

191. Tian, X.; Li, J.; Ma, Z.M.; Zhao, C.; Wan, D.F.; Wen, Y.M. Role of hepatitis B surface antigen in the development of hepatocellular carcinoma: Regulation of lymphoid enhancer-binding factor 1. J. Exp. Clin. Cancer Res. 2009, 28, 58. [CrossRef] [PubMed]

(C) 2020 by the authors. Licensee MDPI, Basel, Switzerland. This article is an open access article distributed under the terms and conditions of the Creative Commons Attribution (CC BY) license (http://creativecommons.org/licenses/by/4.0/). 